\title{
THERMOSENSITIVE FLUORESCENT LIPOSOMES
}

\author{
Lim Jin Heng \\ School of Physical and Mathematical Sciences
}

\author{
Dr Chi-Lik Ken Lee \\ School of Physical and Mathematical Sciences
}

\begin{abstract}
Liposomes are versatile nanomaterials used in a variety of applications such as drug delivery and bioimaging. In this study, three asymmetrical squaraine dyes were synthesized and embedded in liposomes in the efforts to find a suitable dye that can be used for bioimaging procedures involving liposomes. The optical properties of the synthesized dyes as well as their liposomes were studied and compared to the previously synthesized asymmetrical squaraine dye SQR22 and its liposome form.
\end{abstract}

\section{INTRODUCTION}

Liposomes are nanovesicles made up of at least one phospholipid bilayer ${ }^{1}$. They consist of a small aqueous core and a lipid bilayer as shown in Figure $1 \mathrm{a}^{2}$. Liposomes were first discovered in 1960 and is known for their biocompatibility which increases their efficacy and reduces the toxicity of the therapeutic substances they encapsulate such as anti-cancer drugs and antibiotics ${ }^{3-6}$. There were studies where macromolecules such as DNA and protein were delivered to their intended target using liposomes ${ }^{7,8}$. Figure 1a shows the general structure of liposomes.

a)

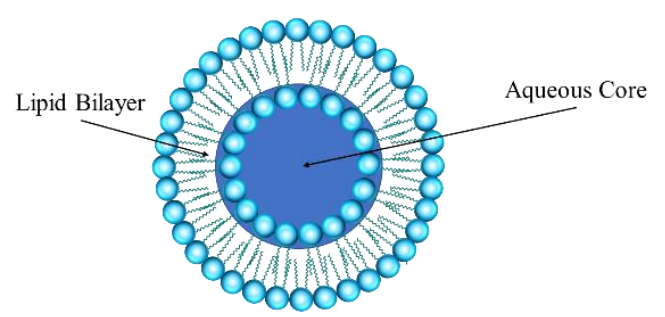

b)

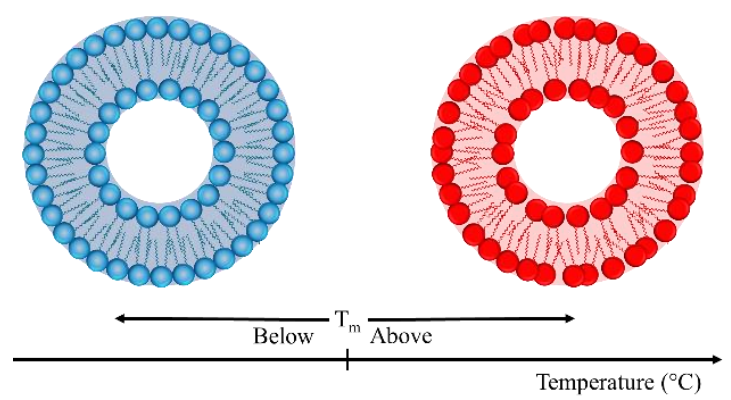

An interesting characteristic of phosphatidylcholine (PC) class liposomes is that these liposomes are able to interchange between a crystalline structure and a gel-like structure at the phase transition temperature $\left(\mathrm{T}_{\mathrm{m}}\right)$ shown in Figure 1b. This could be because the PC chains are all in the trans arrangement below the $T_{m}$ and as the temperature of the environment goes above the $\mathrm{T}_{\mathrm{m}}$, the chains adopt more gauche conformations along the PC chains resulting in a more disordered gel phase $^{9,10} . \mathrm{T}_{\mathrm{m}}$ can be controlled by changing the length of the PC chain making up the liposome or by changing the composition of the lipid bilayer ${ }^{11,12}$.

Other than therapeutic agents, liposomes can be used to encapsulate organic dyes for bioimaging purposes ${ }^{13}$. Organic dyes such as $\pi$-conjugated chromophores have very strong optical properties in the near-infrared region (NIR). Hence, they are commonly used for photodynamic therapy (PDT) as well as bioimaging ${ }^{14-21}$. However, they tend to undergo chemical and photochemical degradation when introduced into aqueous biological systems. The $\pi$-conjugated dyes also tend to aggregate, influencing their optical properties. Liposomes are suitable to perform molecular encapsulation of the dyes as they provide an environment in which the aggregation of the dyes can be controlled. The biocompatibility of liposomes allows their usage in drug delivery systems as well as protection for molecular cargo in biological system environments ${ }^{22}$.

Squaraine (SQR) dye is a class of organic dyes that possess strong and narrow absorption and emission bands in the near-infrared (NIR) region of the electromagnetic spectrum ${ }^{23-25}$. This class of dyes are the derivatives of squaric acid containing a fourmembered ring as their core and two other substituent groups. They were first discovered by Treibs and Jacobs in $1965^{26}$ and are extensively studied due to their strong absorbance and fluorescence in the NIR as well as their stability owing to the zwitterionic resonance $^{27}$.

Figure 1. a) Structure of liposomes. b) Phase Transition of liposomes. 


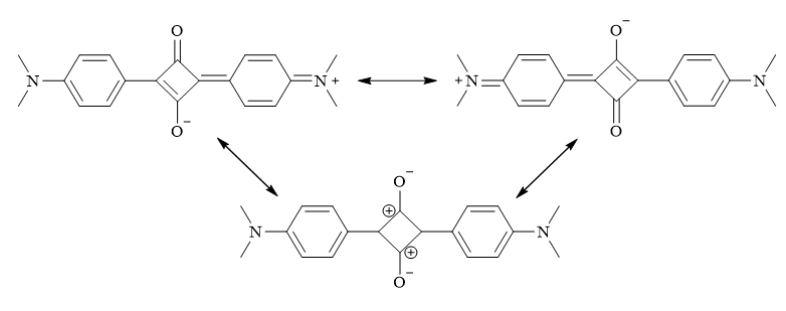

Figure 2. Zwitterionic resonance in squaraine dyes.

There are two classes of SQR dyes: symmetrical and asymmetrical SQR dyes. Figure 3 depicts the differences.

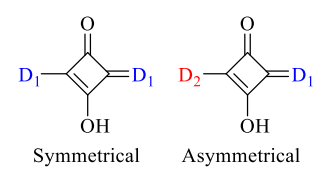

Figure 3. Symmetrical and asymmetrical SQR dyes.

Squaraine dyes contain the central squaric core which behaves as a strong electron acceptor (A). This group is connected to two other electron donating groups (D). Symmetrical squaraine dye occurs when the two $\mathrm{D}$ groups are identical while asymmetrical dye occurs when they are different. Asymmetrical SQR dyes are gaining a lot of attention in the recent years because their synthesis can be controlled easily. The orientation of their attachment to biomolecules can be manipulated $\operatorname{too}^{28}$. This eases the use of the dye for diagnostic purposes.

The thermosensitive property of SQR dye embedded liposomes arises from the degree of aggregation of the dyes within the liposome as it undergoes phase changes when the temperature goes above and below $\mathrm{T}_{\mathrm{m}}$. Aggregation of the dyes results in fluorescence quenching while disaggregation of the dyes induces fluorescence ${ }^{29}$.

SQR22 (Figure 4), an asymmetrical dye first synthesized by $\mathrm{K}$. Sou et al. was successfully encapsulated in the liposome with its optical and thermosensitive properties measured ${ }^{29}$. However, in the unpublished results, during the bioimaging procedure, migration of the dyes from the lipid bilayer to the cell was observed. This phenomenon is undesirable for this application. A possible solution includes increasing the interaction strength between the dyes and the lipid bilayer. Two possible methods include increasing the hydrophobicity of the dyes and introducing a charge to the dyes. There is also a need for the maintenance of the optical properties of the dyes as well as the dye-liposome complexes in the NIR.

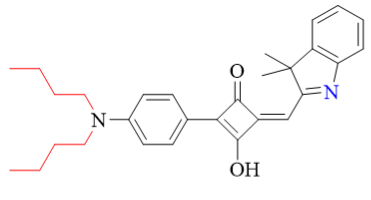

SQR22

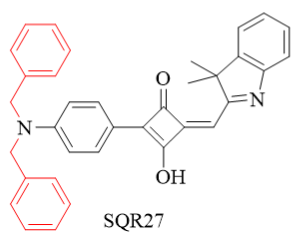

SQR27
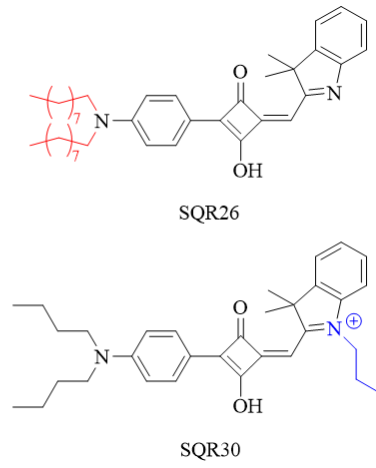

$\mathrm{SQR} 30$
Figure 4. Analogues of SQR22.

SQR26 and SQR27 differ from SQR22 in the aniline moiety. SQR26 has longer 9-carbon chains while SQR27 has bulkier phenyl groups. These modifications increase the hydrophobicity of the dyes. SQR30 differs from SQR22 in the indolenine moiety where the nitrogen atom has been functionalised with a propyl group which introduces a charge to the dye. The work on these three dyes is crucial for the determination of suitable dyes to obtain ideal liposomes for bioimaging purposes.

\section{MATERIALS AND METHODS}

Aniline, N,N-dibutylaniline, 1-bromononane, 1bromopropane, 3,4-Dihydroxycyclobut-3-ene-1,2dione, and 2,3,3-trimethylindolenine reagents were of analytical grade, obtained from commercial suppliers and used without further purification.

${ }^{1} \mathrm{H}$ NMR spectra were recorded on JEOL ECA 400 $\mathrm{MHz}$ spectrometer at $25^{\circ} \mathrm{C}$ (internal standard reference $\mathrm{SiMe}_{4}$ and $\mathrm{CDCl}_{3}$ as solvent). Chemical shifts $(\delta)$ in units of parts per million $(\mathrm{ppm})$ downfield from $\mathrm{SiMe}_{4}(\delta 0.0)$. Multiplicities are recorded as: $\mathrm{s}$ (singlet); d (doublet); t (triplet); q (quartet); dd (doublets of doublet); or $\mathrm{m}$ (multiplet). The number of protons ( $\mathrm{n}$ ) for a given peak is indicated by $\mathrm{nH}$.

${ }^{13} \mathrm{C}$ NMR spectra were recorded on JEOL ECA 400 $\mathrm{MHz}$ spectrometer at $25^{\circ} \mathrm{C}$ (internal standard reference $\mathrm{SiMe}_{4}$ and $\mathrm{CDCl}_{3}$ as solvent).

Spectra for fluorescence were recorded on Agilent Cary Eclipse Fluorescence Spectrophotometer.

Spectra for UV-Visible Absorbance were recorded on Agilent Cary 300 UV-Visible Spectrophotometer.

Extrusion of liposomes were conducted with Evonik Lipex $10 \mathrm{~mL}$ Extruder with membranes from Millipore and Whatman. 
Size characterisation and Zeta Potential measurements were done on the Malvern Panalytical Zetasizer Nano ZSP.

Scheme 1. Synthesis of SQR dyes.

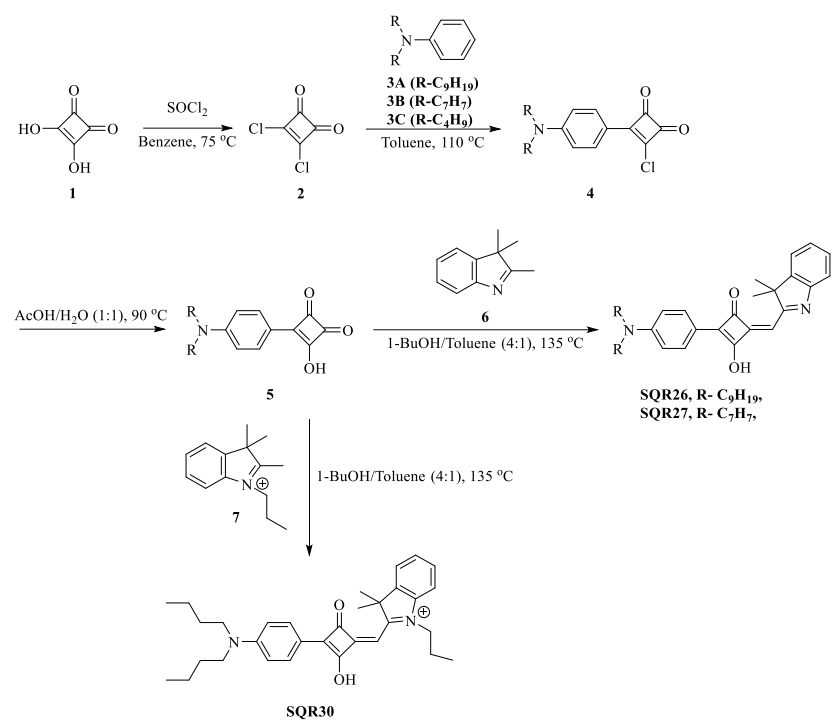

Synthesis of Compound 3A

Aniline (10.0 mmol, 1.0 equiv) and $\mathrm{K}_{2} \mathrm{CO}_{3}(30.0$ mmol, 3.0 equiv) were dissolved in DMF $(15.0 \mathrm{~mL})$ and heated to $90^{\circ} \mathrm{C}$. 1-bromononane $(22.5 \mathrm{mmol}, 2.25$ equiv) was added dropwise to the heated solution and the mixture was stirred for 48 hours.

Gravitational filtration was performed after cooling and the filtrate was washed thrice with deionised water. The combined aqueous layer was extracted ether thrice. The combined organic layers were left to dry overnight with $\mathrm{MgSO}_{4}$. The mixture was filtered. The filtrate was concentrated under reduced pressure.

Purification by column chromatography was done with hexane eluent to obtain Compound 3A (1523.6 $\mathrm{mg}, 44.1 \%) .{ }^{1} \mathrm{H}$ NMR $\left(400 \mathrm{MHz}, \mathrm{CDCl}_{3}\right): \delta$ 7.18-7.26 $(\mathrm{m}, 2 \mathrm{H}) ; 6.60-6.65(\mathrm{~m}, 3 \mathrm{H}) ; 3.23-3.26(\mathrm{t}, J=7.8 \mathrm{~Hz}$, $4 \mathrm{H}) ; 1.56-1.60(\mathrm{~m}, 4 \mathrm{H}) ; 1.29-1.32(\mathrm{~m}, 24 \mathrm{H}) ; 0.88-0.91$ (t, $J=7.08 \mathrm{~Hz}, 6 \mathrm{H})$. MS (ESI): Found $\mathrm{m} / \mathrm{z}$ 346.40. Calcd for $\mathrm{C}_{24} \mathrm{H}_{43} \mathrm{~N}\left[\mathrm{M}^{+}\right]=345.62$.

\section{Synthesis of SQR26}

Compound 1 (4.39 mmol, 1.0 equiv) and thionyl chloride (9.21 mmol, 2.1 equiv) were dissolved in benzene $(10.0 \mathrm{~mL})$ in a round bottom flask and refluxed at $75^{\circ} \mathrm{C}$ for 16 hours. The solvent was removed under reduced pressure. After which compound 3A (4.39 mmol, 1.0 equiv) was added and the final mixture refluxed at $111^{\circ} \mathrm{C}$ for another 6 hours. Ice cold water was added to the reaction mixture and extracted with ethyl acetate. The solvent in the organic layer was removed under reduced pressure. A mixture of acetic acid $(20.0 \mathrm{~mL})$, water $(20.0 \mathrm{~mL})$ and $5 \mathrm{~N} \mathrm{HCl}(2.0 \mathrm{~mL})$ was added, and the reaction mixture was left to reflux at $110^{\circ} \mathrm{C}$ for 3 hours.

The final reaction mixture was cooled in the ice-bath and then extracted with ethyl acetate. The organic layer was concentrated under reduced pressure to yield a dark brown oil which was suspended with a mixture of $n$-butanol (32.0 mL) and toluene $(8.0 \mathrm{~mL})$. Compound 6 ( $4.39 \mathrm{mmol}, 1.0$ equiv) was added to this mixture and left to reflux at $120^{\circ} \mathrm{C}$ for 5 hours.

The crude product was purified by column chromatography with $35 \%$ ethyl acetate in hexane eluent to obtain purified SQR26 $(189.2 \mathrm{mg}, 7.4 \%) .{ }^{1} \mathrm{H}$ NMR (400 MHz, $\left.\mathrm{CDCl}_{3}\right): \delta 8.10-8.11(\mathrm{~m}, 2 \mathrm{H}) ; 7.18$ $7.33(\mathrm{~m}, 4 \mathrm{H}) ; 6.65-6.68(\mathrm{~m}, 2 \mathrm{H}) ; 5.83(\mathrm{~s}, 1 \mathrm{H}) ; 3.34-$ $3.38(\mathrm{t}, J=7.80 \mathrm{~Hz}, 4 \mathrm{H}) ; 1.43-1.49(\mathrm{t}, J=11.66 \mathrm{~Hz}$, $6 \mathrm{H}) ; 1.25-1.33(\mathrm{~m}, 24 \mathrm{H}) ; 0.87-0.91(\mathrm{~s}, 6 \mathrm{H})$. MS(ESI): Found $\mathrm{m} / \mathrm{z}$ 583.50. Calcd for $\mathrm{C}_{39} \mathrm{H}_{54} \mathrm{~N}_{2} \mathrm{O}_{2}\left[\mathrm{M}^{+}\right]=$ 582.87 .

\section{Synthesis of SQR27}

Compound 1 (2.00 mmol, 1.0 equiv) and thionyl chloride (4.00 mmol, 2.0 equiv) were dissolved in benzene $(10 \mathrm{~mL})$ and refluxed at $75^{\circ} \mathrm{C}$ for 5 hours. The solvent was removed under reduced pressure. The oil obtained was resuspended in toluene and Compound $3 B$ ( $2.00 \mathrm{mmol}, 1.0$ equiv) was added. The final mixture refluxed at $111^{\circ} \mathrm{C}$ for 12 hours. Ice-cold water was added to the reaction mixture and extracted with ethyl acetate.The solvent in the organic layer was removed under reduced pressure. A mixture of acetic acid $(20.0 \mathrm{~mL})$, water $(20.0 \mathrm{~mL})$ and $5 \mathrm{~N} \mathrm{HCl}(2.0 \mathrm{~mL})$ was added, and the reaction mixture was left to reflux at $110^{\circ} \mathrm{C}$ for 3 hours.

Vacuum filtration was performed after cooling the final reaction mixture in an ice-bath. A dirty green solid yielded was suspended with a mixture of $n$ butanol $(32.0 \mathrm{~mL})$ and toluene $(8.0 \mathrm{~mL})$. Compound 6 ( $2.00 \mathrm{mmol}, 1.0$ equiv) was added to this mixture and left to reflux at $135^{\circ} \mathrm{C}$ for 16 hours.

The crude product was purified by column chromatography with $45 \%$ ethyl acetate in hexane eluent to obtain purified SQR27 (147.8 $\mathrm{mg}, 14.5 \%)$. ${ }^{1} \mathrm{H}$ NMR $\left(400 \mathrm{MHz}, \mathrm{CDCl}_{3}\right): \delta$ 8.06-8.09 (m, 2H); 7.21-7.35 (m, 14H); 6.81-6.83 (m, 2H); $5.88(\mathrm{~s}, 1 \mathrm{H})$; $4.74(\mathrm{~m}, 4 \mathrm{H}) ; 1.49(\mathrm{~s}, 6 \mathrm{H})$. MS(ESI): Found $\mathrm{m} / \mathrm{z}$ 511.27. Calcd for $\mathrm{C}_{35} \mathrm{H}_{30} \mathrm{~N}_{2} \mathrm{O}_{2}\left[\mathrm{M}^{+}\right]=510.64$.

\section{Synthesis of Compound 7}

Compound 6 (10.00 mmol, 1.0 equiv) was dissolved in toluene $(3.2 \mathrm{~mL})$ in a round bottom flask. This was followed by addition of 1-bromopropane and the 
reaction mixture refluxed at $100^{\circ} \mathrm{C}$ for $3 \mathrm{~h}$. Solvent removal at reduced pressure was done to yield a purple oil which was resuspended in ethyl acetate and washed with water. The aqueous layer was collected and concentrated under reduced pressure to yield Compound 7 (382.3 mg, 14.1\%). ${ }^{1} \mathrm{H}$ NMR (400 MHz, $\left.\mathrm{CDCl}_{3}\right): \delta$ 7.55-7.68 (m, 4H); 4.67-4.71 (t, $J=7.32 \mathrm{~Hz}$, $2 \mathrm{H}) ; 3.09$ (s, 3H) 1.95-2.02 (m, 2H), $1.62(\mathrm{~s}, 6 \mathrm{H}) 1.04$ 1.08 (t, $J=7.38 \mathrm{~Hz}, 3 \mathrm{H})$. MS(ESI): Found $m / z$ 202.26. Calcd for $\mathrm{C}_{14} \mathrm{H}_{20} \mathrm{~N}^{+}\left[\mathrm{M}^{+}\right]=202.32$.

\section{Synthesis of SQR30}

Compound 1 (4.39 mmol, 1.0 equiv) and thionyl chloride (9.21 mmol, 2.1 equiv) were dissolved in benzene $(10.0 \mathrm{~mL})$ in a round bottom flask and refluxed at $75^{\circ} \mathrm{C}$ for 16 hours. The solvent was removed under reduced pressure. After which compound 3C (4.39 mmol, 1.0 equiv) was added and the final mixture refluxed at $111^{\circ} \mathrm{C}$ for another 6 hours. Ice cold water was added to the reaction mixture and extracted with ethyl acetate. The solvent in the organic layer was removed under reduced pressure. A mixture of acetic acid $(20.0 \mathrm{~mL})$, water $(20.0 \mathrm{~mL})$ and $5 \mathrm{~N} \mathrm{HCl}(2.0 \mathrm{~mL})$ was added, and the reaction mixture was left to reflux at $110^{\circ} \mathrm{C}$ for 3 hours.

Vacuum filtration was performed after cooling the final reaction mixture in an ice-bath. A dirty green solid yielded was suspended with a mixture of $n$ butanol $(32.0 \mathrm{~mL})$ and toluene $(8.0 \mathrm{~mL})$. Compound 7 ( $4.39 \mathrm{mmol}, 1.0$ equiv) was added to this mixture and left to reflux at $135^{\circ} \mathrm{C}$ for 16 hours.

The crude product was purified by column chromatography with $50 \%$ ethyl acetate in methanol eluent to obtain purified SQR30 (145.7 mg, 6.8\%). ${ }^{1} \mathrm{H}$ NMR (400 MHz, $\left.\mathrm{CDCl}_{3}\right): \delta 8.10-8.11(\mathrm{~m}, 2 \mathrm{H}) ; 7.18$ $7.33(\mathrm{~m}, 4 \mathrm{H}) ; 6.65-6.68(\mathrm{~m}, 2 \mathrm{H}) ; 5.83(\mathrm{~s}, 1 \mathrm{H}) ; 3.34-$ $3.38(\mathrm{t}, J=7.80 \mathrm{~Hz}, 4 \mathrm{H}) ; 1.43-1.49(\mathrm{t}, J=11.66 \mathrm{~Hz}$, $6 \mathrm{H}) ; 1.25-1.33(\mathrm{~m}, 24 \mathrm{H})$; 0.87-0.91 (s, 6H). MS(ESI): Found $\mathrm{m} / \mathrm{z}$ 485.39. Calcd for $\mathrm{C}_{32} \mathrm{H}_{41} \mathrm{~N}_{2} \mathrm{O}_{2}{ }^{+}\left[\mathrm{M}^{+}\right]=$ 485.69 .

\section{Encapsulation of dye in liposome}

Liposome samples consisting of PC16 and SA with the molar ratio of $\mathrm{PC} 16 / \mathrm{SA} / \mathrm{SQR}$ at $9 / 1 / \mathrm{x}$ where $\mathrm{x}=0.2$, 0.33 and 0.5 . The mixture was dissolved in t-butanol and then freeze dried. The powder was then hydrated with PBS to obtain the lipid concentration of $5 \mathrm{mg} / \mathrm{mL}$. This dispersion is then extruded through filter with pore sizes of $0.2 \mu \mathrm{m}$ followed by $0.1 \mu \mathrm{m}$ and finally $0.05 \mu \mathrm{m}$ thrice at $60^{\circ} \mathrm{C}$ under pressure of nitrogen gas. The resulting solutions are then stored in the $4{ }^{\circ} \mathrm{C}$ refrigerator. The liposomes were characterised for its size and zeta potential.

\section{RESULTS AND DISCUSSION}

Optical properties of the three synthesized dyes were measured and recorded in Table 1.

As seen in Table 1, the Stokes shift of the 3 dyes increases with increasing polarity. The maximum stokes shift occurs in DMF and DMSO solvents for all dyes. This is because the solvents can stabilise the planar form of the SQR dyes in the excited state. This leads to a larger geometric change to the dye compared to non-polar solvents such as hexane ${ }^{30}$. This geometric change could alter the energy gap between the ground state and the first excited energy level where deexcitation gives fluorescence and the energy gap between the ground state and first excited state which absorbance takes place. Therefore, larger Stokes shift is observed in DMF and DMSO.

Based on Table 1, it can be noted that as the carbon chain length on the aniline moiety increases, there is a slight red shift in the absorbance. By substituting the groups on the aniline moiety with a phenyl ring, there is a slight blue shift in absorbance. The introduction of a positive charge to the dye causes the absorbance to blue shift to a larger extent compared to that of with increased hydrophobicity of the dyes.

The red shift in absorbance observed in SQR26 compared to SQR22 could be due to the longer carbon chain on the aniline moiety. The longer carbon chain could have a larger electron donating effect which could have reduced the energy gap between the excited and ground states of the dye. The empty $p$ orbital on the nitrogen atom in SQR30 an as well as the phenyl rings on SQR27 could have contributed to a longer $\pi$-conjugation which could have changed the energy levels of the dye at excited and ground states. This change could increase the abovementioned energy gap. This results in the blue shift of absorbance observed for SQR27 and SQR30.

There is a blue shift in the absorbance for SQR26 and SQR27 when in DMF and DMSO solvents as well as an observed broad absorption band in water for the three dyes. This could be due to the solvatochromic effects of the solvent which leads to the aggregation of the dye in polar solvents. There are 2 types of aggregations ${ }^{31}$. Type $\mathrm{A}$ is a result of face-to-face arrangement of the dye during aggregation and is thermodynamically preferred. Type B is a result of the dyes arranging themselves such that the electron deficient regions of the dye have maximum interactions with electron rich regions of another dye. This type of aggregation is kinetically favoured 
Table 1. Optical data for SQR22 ${ }^{29}$, SQR26 $(6.25 \mu \mathrm{M})$, SQR27 $(25 \mu \mathrm{M})$ and SQR30 $(2.5 \mu \mathrm{M})$ in 14 solvents.

\begin{tabular}{|c|c|c|c|c|c|c|c|c|c|c|c|c|}
\hline \multirow[t]{2}{*}{ Solvent } & \multicolumn{3}{|c|}{ SQR22 } & \multicolumn{3}{|c|}{ SQR26 } & \multicolumn{3}{|c|}{ SQR27 } & \multicolumn{3}{|c|}{ SQR30 } \\
\hline & $\begin{array}{c}\lambda_{\text {abs }} \\
(\mathbf{n m})\end{array}$ & $\begin{array}{c}\lambda_{\mathrm{em}} \\
(\mathrm{nm})\end{array}$ & $\begin{array}{c}\text { Stokes } \\
\text { Shift (nm) }\end{array}$ & $\begin{array}{l}\lambda_{\text {abs }} \\
(\mathbf{n m})\end{array}$ & $\begin{array}{c}\lambda_{\mathrm{em}} \\
(\mathbf{n m})\end{array}$ & $\begin{array}{c}\text { Stokes } \\
\text { Shift (nm) }\end{array}$ & $\begin{array}{l}\lambda_{\text {abs }} \\
(\mathbf{n m})\end{array}$ & $\begin{array}{c}\lambda_{\mathrm{em}} \\
(\mathbf{n m})\end{array}$ & $\begin{array}{c}\text { Stokes } \\
\text { Shift (nm) }\end{array}$ & $\begin{array}{c}\lambda_{\text {abs }} \\
(\mathbf{n m})\end{array}$ & $\begin{array}{c}\lambda_{\mathrm{em}} \\
(\mathbf{n m})\end{array}$ & $\begin{array}{c}\text { Stokes } \\
\text { Shift (nm) }\end{array}$ \\
\hline Hexane & 629 & 640 & 11 & 631 & 640 & 9 & 621 & 632 & 11 & 622 & 629 & 7 \\
\hline Toluene & 636 & 655 & 19 & 637 & 653 & 16 & 625 & 645 & 20 & 632 & 645 & 13 \\
\hline Benzene & 637 & 656 & 19 & 637 & 655 & 18 & 626 & 645 & 19 & 633 & 648 & 15 \\
\hline Dichloromethane & 633 & 659 & 26 & 635 & 662 & 27 & 617 & 647 & 30 & 628 & 650 & 22 \\
\hline THF & 633 & 660 & 27 & 634 & 660 & 26 & 620 & 650 & 30 & 626 & 648 & 22 \\
\hline Ethanol & 631 & 662 & 31 & 633 & 662 & 29 & 617 & 652 & 35 & 622 & 650 & 28 \\
\hline Methanol & 628 & 662 & 34 & 631 & 662 & 31 & 612 & 650 & 38 & 620 & 653 & 33 \\
\hline Acetone & 629 & 663 & 34 & 631 & 663 & 32 & 614 & 652 & 38 & 622 & 650 & 28 \\
\hline Acetonitrile & 626 & 663 & 37 & 628 & 665 & 37 & 609 & 650 & 41 & 620 & 653 & 33 \\
\hline DMF & 474 & 552 & 78 & 476 & 672 & 196 & 469 & 658 & 189 & 629 & 660 & 31 \\
\hline DMSO & 477 & 565 & 88 & 480 & 673 & 193 & 473 & 663 & 190 & 633 & 665 & 32 \\
\hline Water & $595^{\mathrm{a}}$ & NIL & NA & $593^{\mathrm{a}}$ & NIL & $\mathrm{NA}$ & $582^{\mathrm{a}}$ & NIL & $\mathrm{NA}$ & $587^{\mathrm{a}}$ & NIL & NA \\
\hline
\end{tabular}

In Table 1, the four dyes display Type B aggregation in water where the hydrophobic effects of the alkyl and phenyl substituents on the aniline could have influenced the free energy of the dye such that it is the most stable with Type B aggregation. In DMF and DMSO, SQR26 and SQR27 display Type A aggregation which results in a hypsochromic and hypochromic shifts of the absorption of a nonaggregated dye. This leads to the two absorption bands observed in the 450-500 nm and in the 600-700 nm regions. The aggregation effect can also be observed in the decreasing fluorescence intensity with increasing polarity of the solvent as the aggregation of the dyes causes quenching of the fluorescence in the polar solvents.

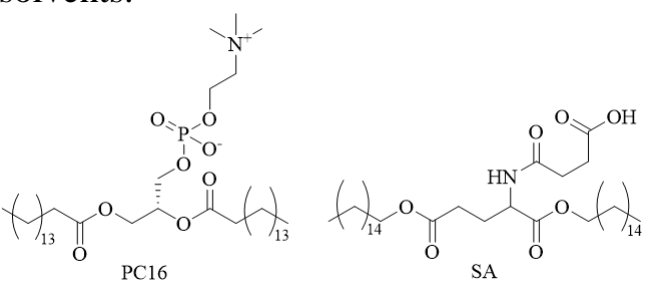

Figure 5. Structure of PC16 and SA lipids used for liposome.

The three dyes were then embedded into the liposomes of PC16/SA composition with different concentrations, $2.0 \mathrm{~mol} \%, 3.3 \mathrm{~mol} \%$ and $5.0 \mathrm{~mol} \%$. The size and zeta potential of these liposomes were measured along with their optical and thermosensitive properties (Table S1 and Figure S1).

Comparing data from Table 2 with data from Table 1, it can be observed that the SQR26 liposome display a red shift while SQR27 and SQR30 maintained the absorbances from their native state. Reasons for this observation is still under study.
Table 2. Optical properties for the SQR dye embedded liposomes at 3 different concentrations.

\begin{tabular}{cccc}
\hline Dye & PC16/SA/SQR $^{\mathbf{a}}$ & $\begin{array}{c}\lambda_{\max } \\
(\mathbf{n m})\end{array}$ & $\begin{array}{c}\lambda_{\mathrm{em}}{ }^{\mathbf{b}} \\
(\mathbf{n m})\end{array}$ \\
\hline \multirow{3}{*}{ SQR26 } & $9 / 1 / 0.2$ & 656 & 675 \\
& $9 / 1 / 0.33$ & 657 & 682 \\
& $9 / 1 / 0.5$ & 657 & 679 \\
\hline \multirow{3}{*}{ SQR27 } & $9 / 1 / 0.2$ & 617 & 650 \\
& $9 / 1 / 0.33$ & 617 & 651 \\
& $9 / 1 / 0.5$ & 618 & 653 \\
\hline \multirow{3}{*}{ SQR30 } & $9 / 1 / 0.2$ & 622 & 650 \\
& $9 / 1 / 0.33$ & 624 & 647 \\
& $9 / 1 / 0.5$ & 624 & 648 \\
\hline
\end{tabular}

${ }^{\mathrm{a}}$ Molar ratio of components. ${ }^{\mathrm{b}}$ Fluorescence readings taken at $50{ }^{\circ} \mathrm{C}$.

Table 3. Optical properties of SQR22 29 , SQR26, SQR27 and SQR30 liposomes at 3.3\% concentration.

\begin{tabular}{cccc}
\hline Dye & $\begin{array}{c}\lambda_{\text {abs }} \\
(\mathbf{n m})\end{array}$ & $\begin{array}{c}\boldsymbol{\lambda}_{\text {em }}{ }^{\mathrm{a}} \\
(\mathbf{n m})\end{array}$ & $\begin{array}{c}\text { Stokes Shift } \\
(\mathbf{n m})\end{array}$ \\
\hline SQR22 & 636 & 664 & 28 \\
SQR26 & 657 & 682 & 25 \\
SQR27 & 617 & 651 & 34 \\
SQR30 & 624 & 647 & 23 \\
\hline
\end{tabular}

In Table 3, SQR22 and SQR26 have similar Stokes Shift which could be due to the carbon chains on the aniline moiety differed by the chain length which has a small influence on the Stokes Shift. SQR27 has the largest Stokes Shift of the four which possibly be due to the bulky phenyl groups on the aniline moiety. SQR30 has the smaller Stokes Shift which could be due to the charged indolenine moiety. Possible causes for this observation include the difference in interactions between the dyes and the liposomes which results in changed extents of geometric changes to the dyes at ground state and excited state altering the energy gaps and hence, influencing the Stokes Shift obtained. 

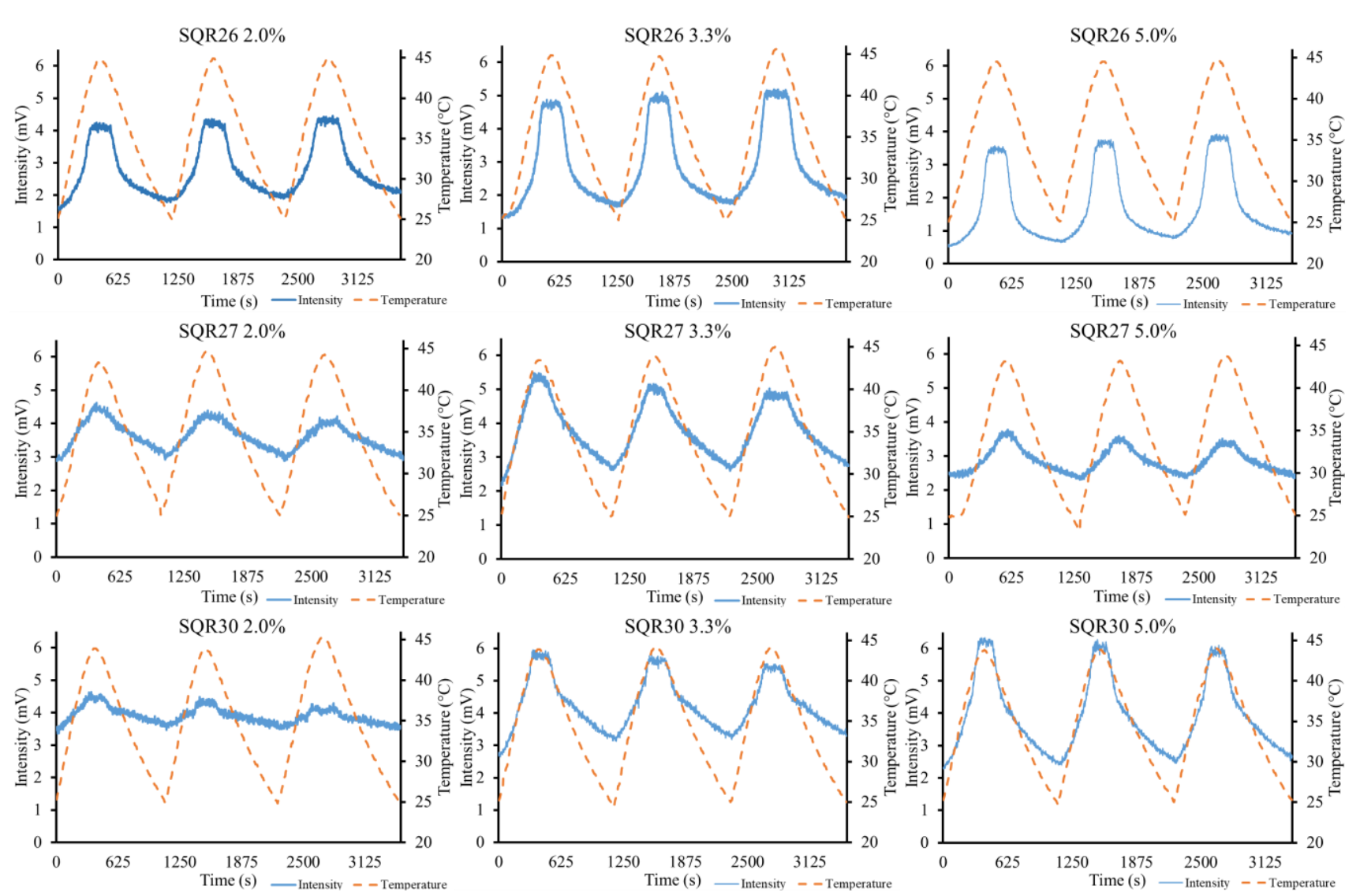

Figure 6. Thermosensitivity profiles for the 9 liposomes containing the 3 dyes at 3 different concentrations.
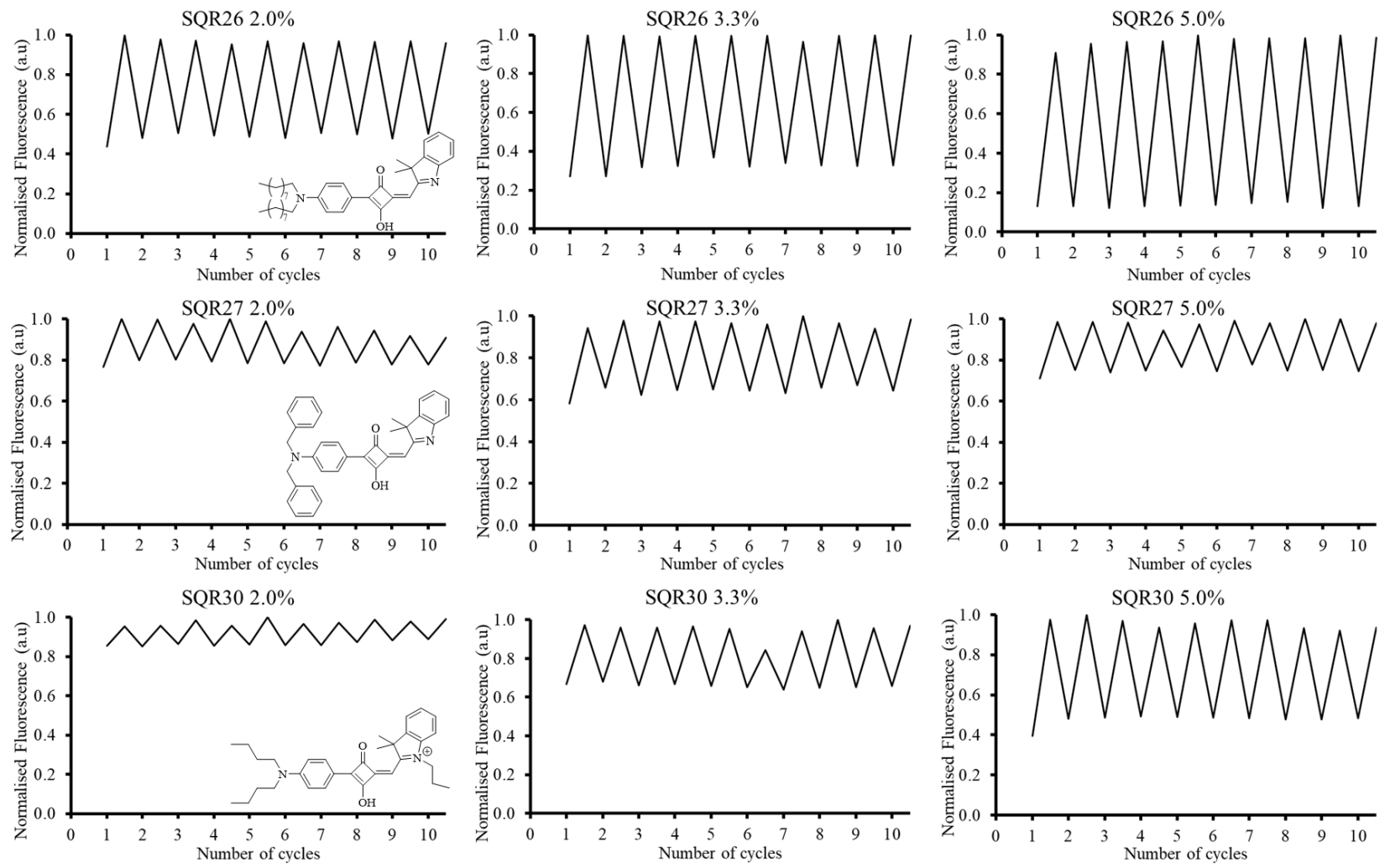

Figure 7. Thermoswitchability profiles for the 9 liposomes containing the 3 dyes with 3 different concentrations. 
Based on Figure 6, it can be concluded that the liposomes synthesized are thermosensitive. As the temperature of the solution increases above $T_{m}$, fluorescence intensity increases. When the temperature falls, the intensity decreases.

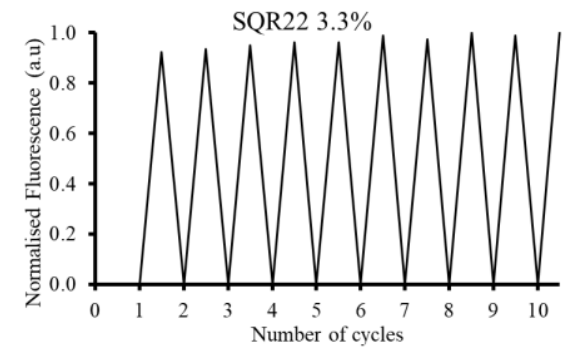

Figure 8. Thermoswitchability profile for liposome containing SQR $22^{29}$ at $3.3 \%$ concentration.

Comparing the thermoswitchability profiles in Figures 7 and 8 , it can be observed that dyes have not achieved the optimum thermosensitive profile to get the same thermoswitchable profile as SQR22 in the liposome. Hence, optimisation of the thermosensitivity needs to be done by optimising the concentration of the dye in the liposome. This is because each individual dye has their optimal concentration in the liposome which gives the best thermosensitivity.

\section{CONCLUSION}

Three asymmetrical squaraine dyes have been synthesized and characterized optically. After which they were embedded in liposomes. These liposomes were characterized optically and for their thermosensitive and thermoswitchable properties. Future works include the tests for the migration phenomenon of the dye during bioimaging as well as to determine the optimum concentration of the dye in the liposome which provides optimum thermosensitivity profile. This study can kickstart further studies into the Quantitative Structure Activity Relationship (QSAR) for asymmetrical squaraine dyes with modifications done to the parent SQR22 asymmetrical dye either by changing the substituents of the 2 groups directly connected to the squaric core or by substituting the squaric core with a croconic core for studies in the newly explored croconaine dyes ${ }^{32}$.

\section{REFERENCES}

1. A. Gonzalez Gomez and Z. Hosseinidoust, ACS Infectious Diseases, 2020, 6, 896-908.

2. C. Has and P. Sunthar, Journal of Liposome Research, 2020, 30, 336-365.

3. A. D. Bangham and R. W. Horne, Nature, 1962, 196, 952-953.

4. G. Wang, in Drug Delivery, 2005, DOI: https://doi.org/10.1002/0471475734.ch19, pp. 411-434.

5. D. C. Drummond, O. Meyer, K. Hong, D. B. Kirpotin and D. Papahadjopoulos, Pharmacological Reviews, 1999, 51, 691.

6. H. Pinto-Alphandary, A. Andremont and P. Couvreur, International Journal of Antimicrobial Agents, 2000, 13, 155-168.

7. M. Nishikawa and M. Hashida, Biological and Pharmaceutical Bulletin, 2002, 25, 275-283.

8. M. Rao and C. R. Alving, Advanced Drug Delivery Reviews, 2000, 41, 171-188.

9. L. H. Lindner and M. Hossann, Current Opinion in Drug Discovery \& Development, 2010, 13, 111-123.

10. P. K. J. Kinnunen, Chemistry and Physics of Lipids, 1991, 57, 375-399.

11. K. M. G. Taylor and R. M. Morris, Thermochimica Acta, 1995, 248, 289-301.

12. J. Chen, D. Cheng, J. Li, Y. Wang, J.-x. Guo, Z.p. Chen, B.-c. Cai and T. Yang, Drug Development and Industrial Pharmacy, 2013, 39, 197-204.

13. Y. Xia, C. Xu, X. Zhang, P. Ning, Z. Wang, J. Tian and X. Chen, Nanoscale, 2019, 11, 58225838.

14. K. König, Journal of Microscopy, 2000, 200, 83-104.

15. G. Xia and H. Wang, Journal of Photochemistry and Photobiology C: Photochemistry Reviews, 2017, 31, 84-113.

16. R. R. Avirah, D. T. Jayaram, N. Adarsh and D. Ramaiah, Organic \& Biomolecular Chemistry, 2012, 10, 911-920.

17. F.-P. Gao, Y.-X. Lin, L.-L. Li, Y. Liu, U. Mayerhöffer, P. Spenst, J.-G. Su, J.-Y. Li, F. Würthner and H. Wang, Biomaterials, 2014, 35, 1004-1014.

18. S. Sreejith, J. Joseph, M. Lin, N. V. Menon, P. Borah, H. J. Ng, Y. X. Loong, Y. Kang, S. W.K. Yu and Y. Zhao, ACS Nano, 2015, 9, 56955704.

19. C.-L. Sun, Q. Liao, T. Li, J. Li, J.-Q. Jiang, Z.-Z. Xu, X.-D. Wang, R. Shen, D.-C. Bai, Q. Wang, 
S.-X. Zhang, H.-B. Fu and H.-L. Zhang,

Chemical Science, 2015, 6, 761-769.

20. R. Jetty, Y. P. Bandera, M. A. Daniele, D.

Hanor, H.-I. Hung, V. Ramshesh, M. F.

Duperreault, A.-L. Nieminen, J. J. Lemasters

and S. H. Foulger, Journal of Materials

Chemistry B, 2013, 1, 4542-4554.

21. Y.-D. Lee, C.-K. Lim, S. Kim, I. C. Kwon and J.

Kim, Advanced Functional Materials, 2010, 20,

2786-2793.

22. E. Arunkumar, C. C. Forbes and B. D. Smith, European Journal of Organic Chemistry, 2005, 2005, 4051-4059.

23. K. D. Volkova, V. B. Kovalska, A. L. Tatarets, L. D. Patsenker, D. V. Kryvorotenko and S. M. Yarmoluk, Dyes and Pigments, 2007, 72, 285292.

24. H. Nakazumi, T. Ohta, H. Etoh, T. Uno, C. L. Colyer, Y. Hyodo and S. Yagi, Synthetic Metals, 2005, 153, 33-36.

25. E. Terpetsching, H. Szmacinski and J. R. Lakowicz, Analytica Chimica Acta, 1993, 282, 633-641.

26. A. Treibs and K. Jacob, Angewandte Chemie International Edition in English, 1965, 4, 694694.

27. A. Ajayaghosh, Accounts of Chemical Research, 2005, 38, 449-459.

28. S. Khopkar and G. Shankarling, Dyes and Pigments, 2019, 170, 107645.

29. K. Sou, L. Y. Chan, S. Arai and C.-L. K. Lee, Scientific Reports, 2019, 9, 17991.

30. X. Liu, B. Cho, L.-Y. Chan, W. L. Kwan and C.L. Ken Lee, RSC Advances, 2015, 5, 106868106876.

31. A. McKerrow, E. Buncel and P. Kazmaier, Canadian Journal of Chemistry, 2011, 73, 16051615.

32. D. E. Lynch and D. G. Hamilton, European Journal of Organic Chemistry, 2017, 2017, 3897-3911. 
Supporting Information

\section{Thermosensitive Fluorescent Liposomes}

Lim Jin Heng, Dr Chi-Lik Ken Lee

\section{Contents}

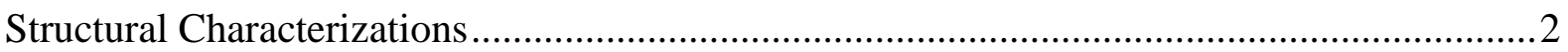

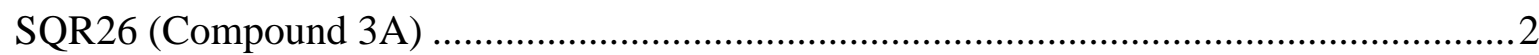

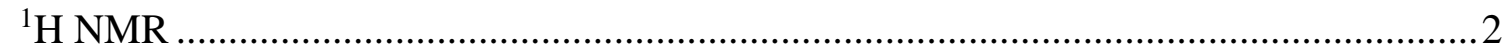

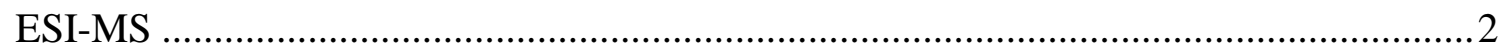

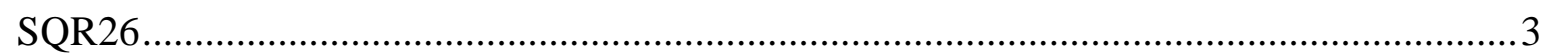

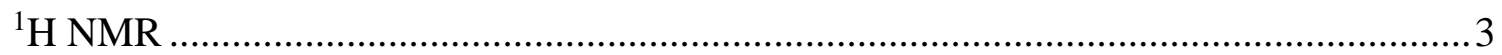

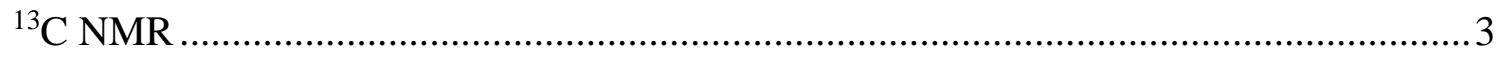

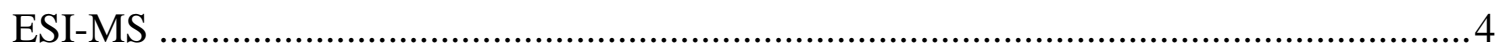

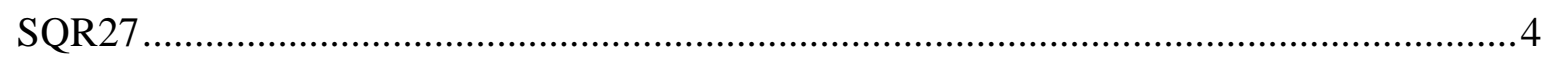

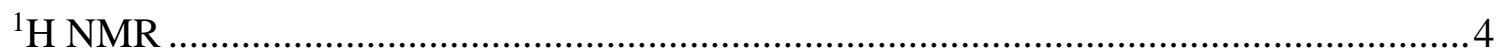

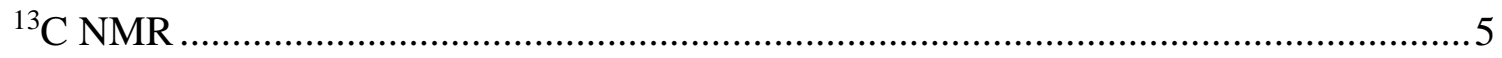

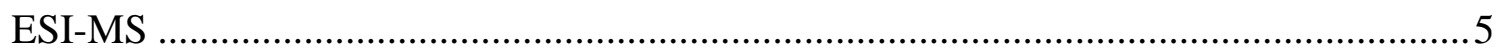

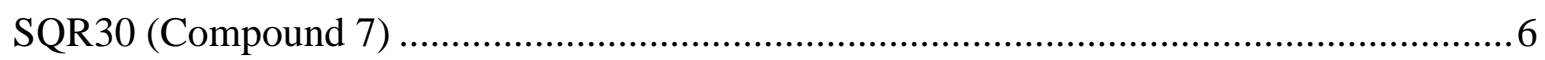

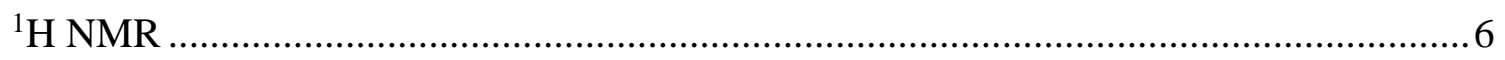

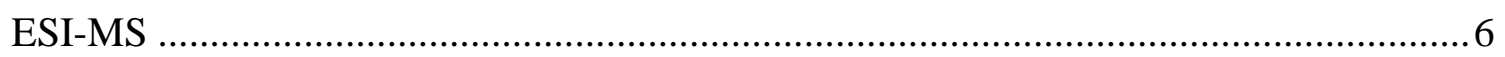

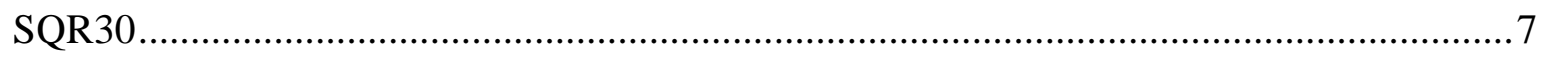

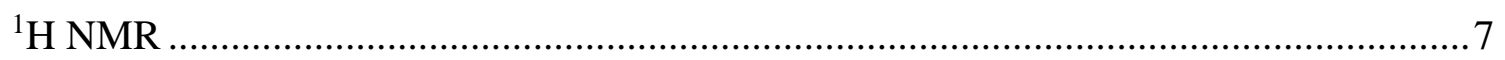

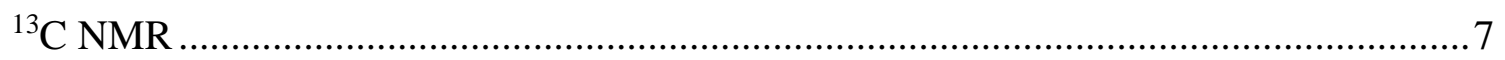

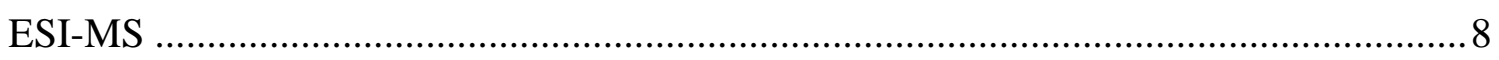

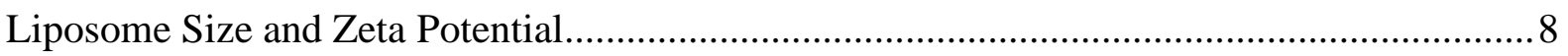

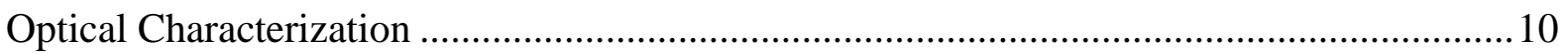

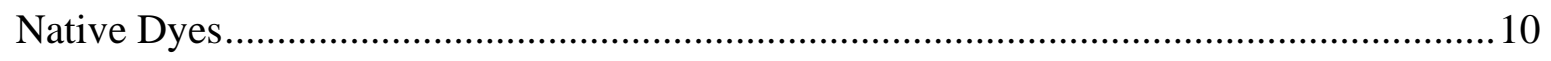

UV-Vis Absorbance (Left) and Fluorescence (Right) ............................................... 10

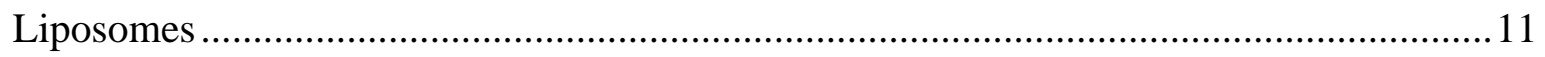

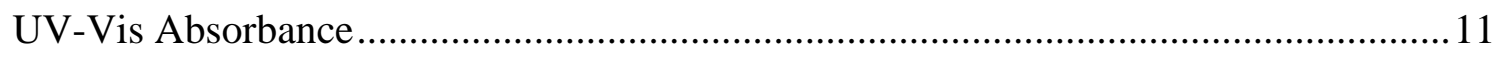

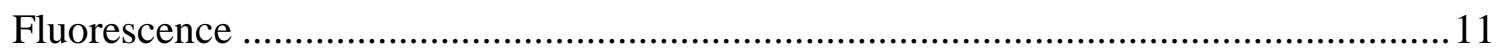




\section{Structural Characterizations}

SQR26 (Compound 3A)

${ }^{1} \mathrm{H}$ NMR

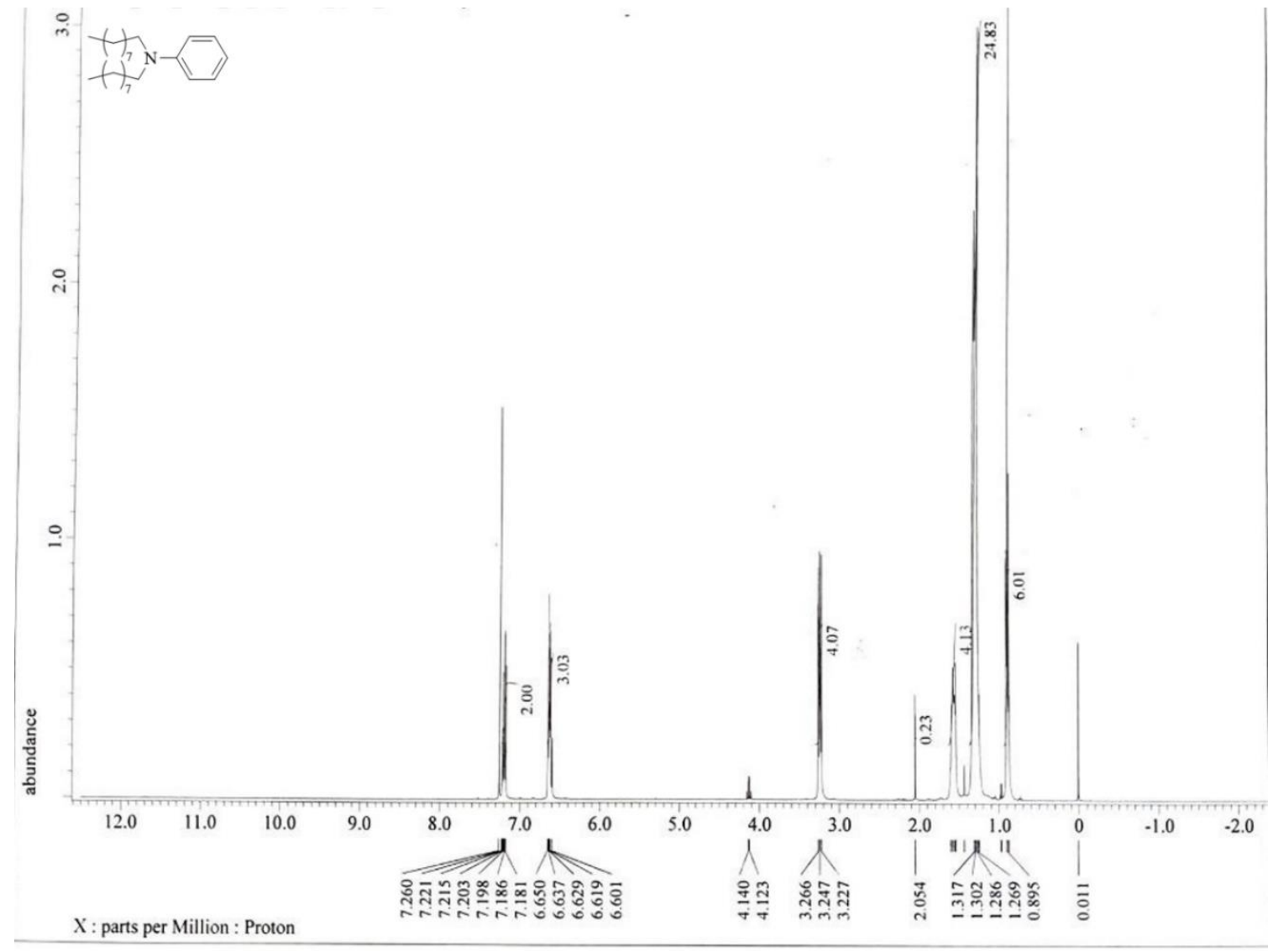

\section{ESI-MS}

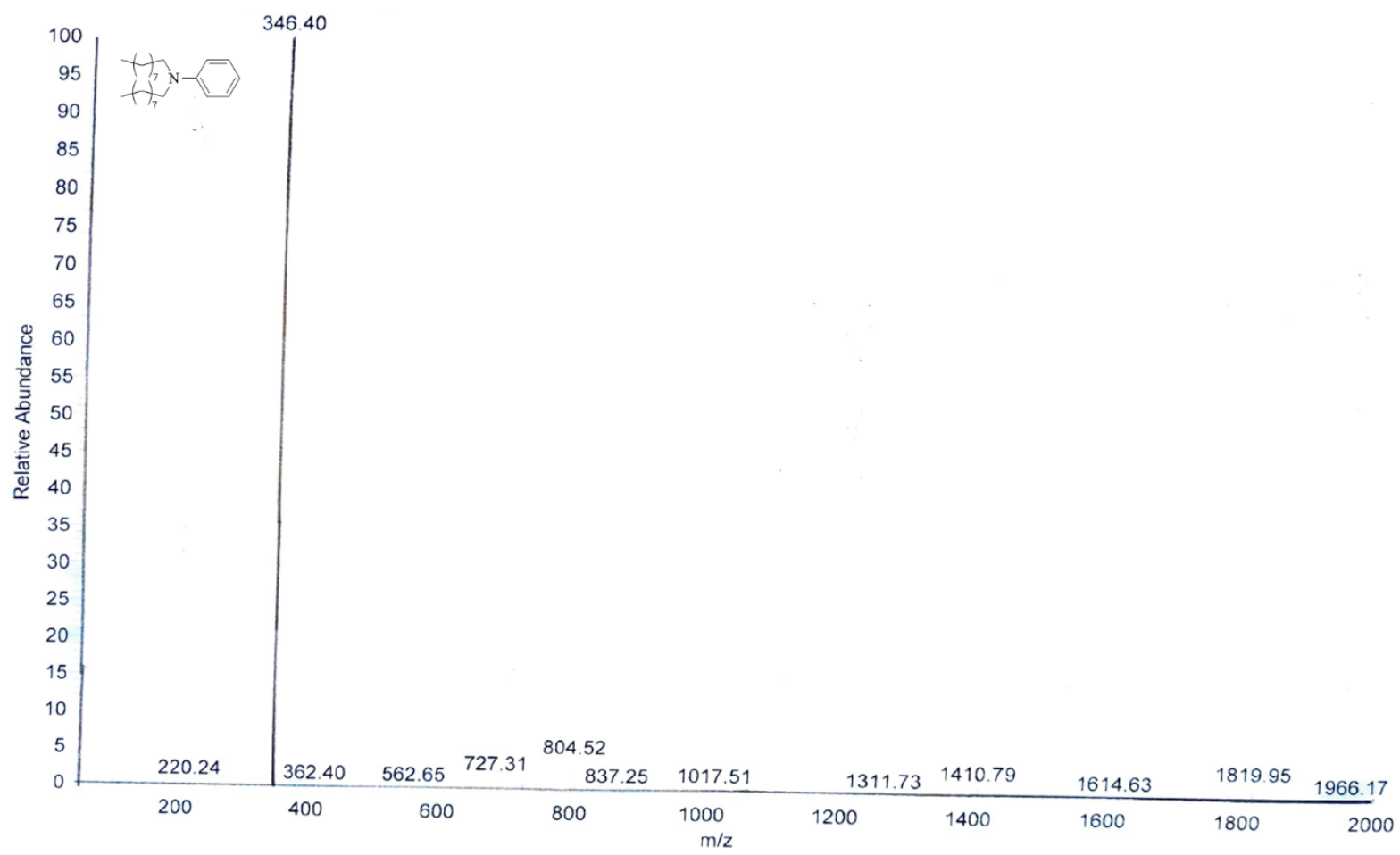


SQR26

${ }^{1}$ H NMR

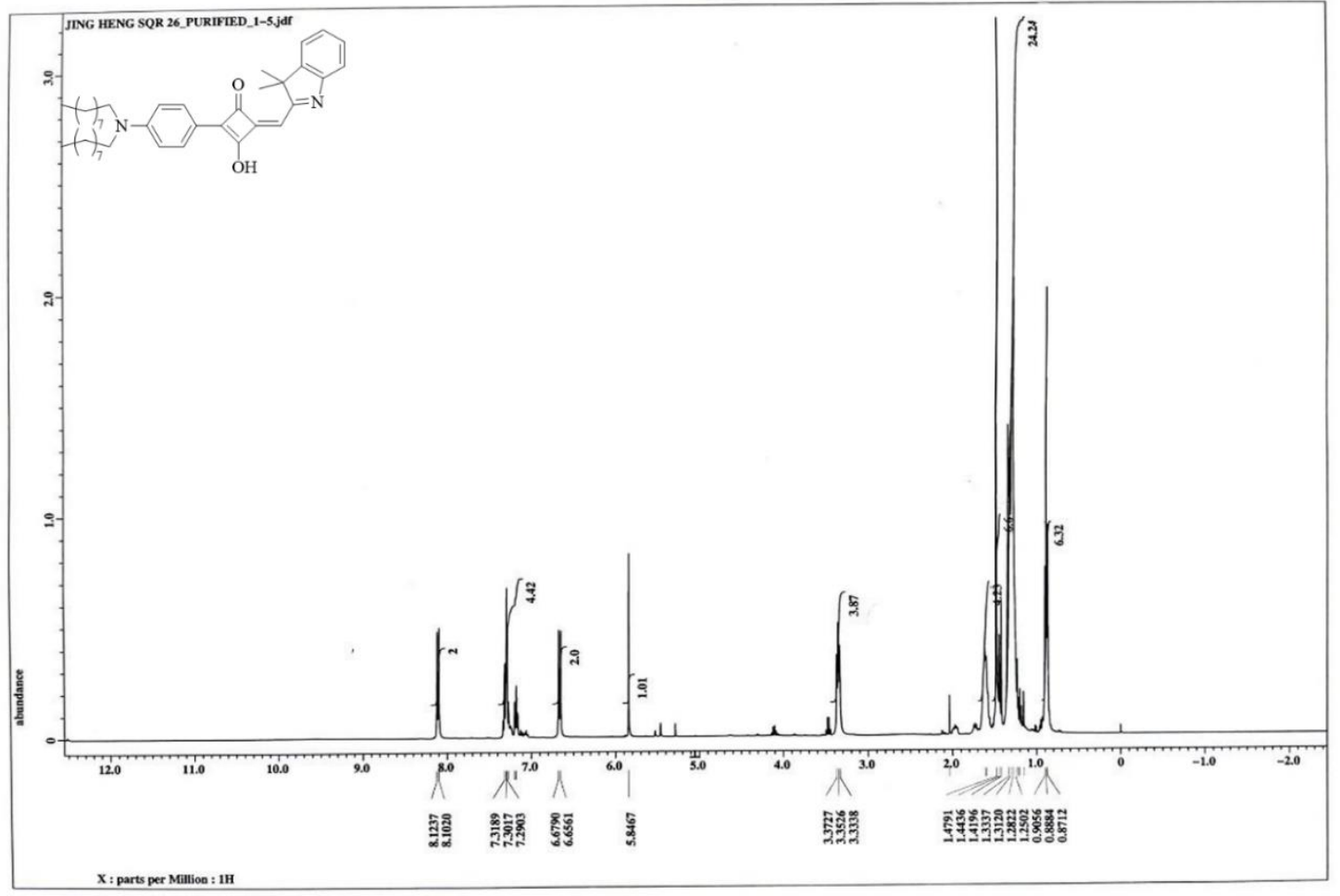

\section{${ }^{13} \mathrm{C}$ NMR}

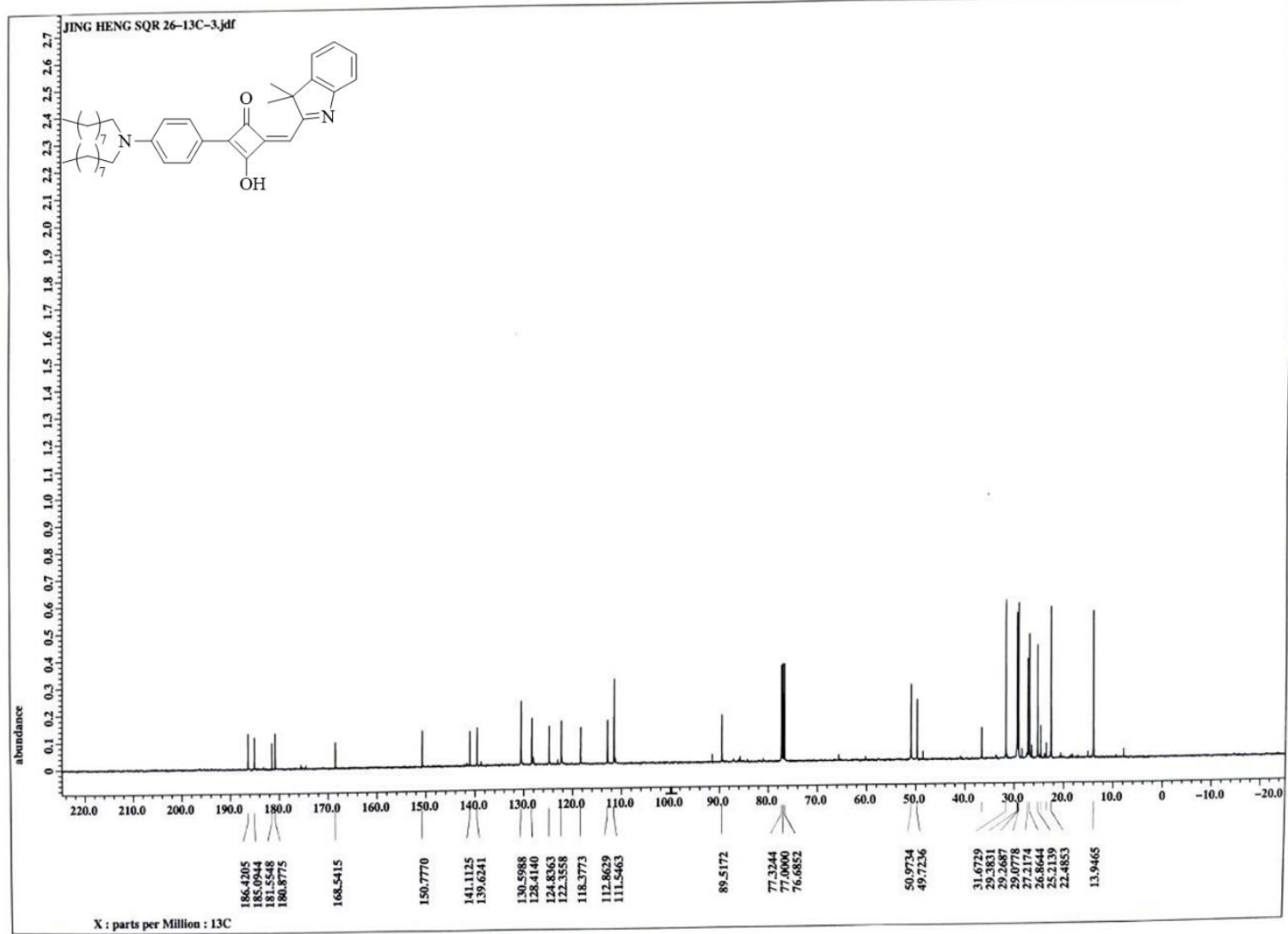




\section{ESI-MS}

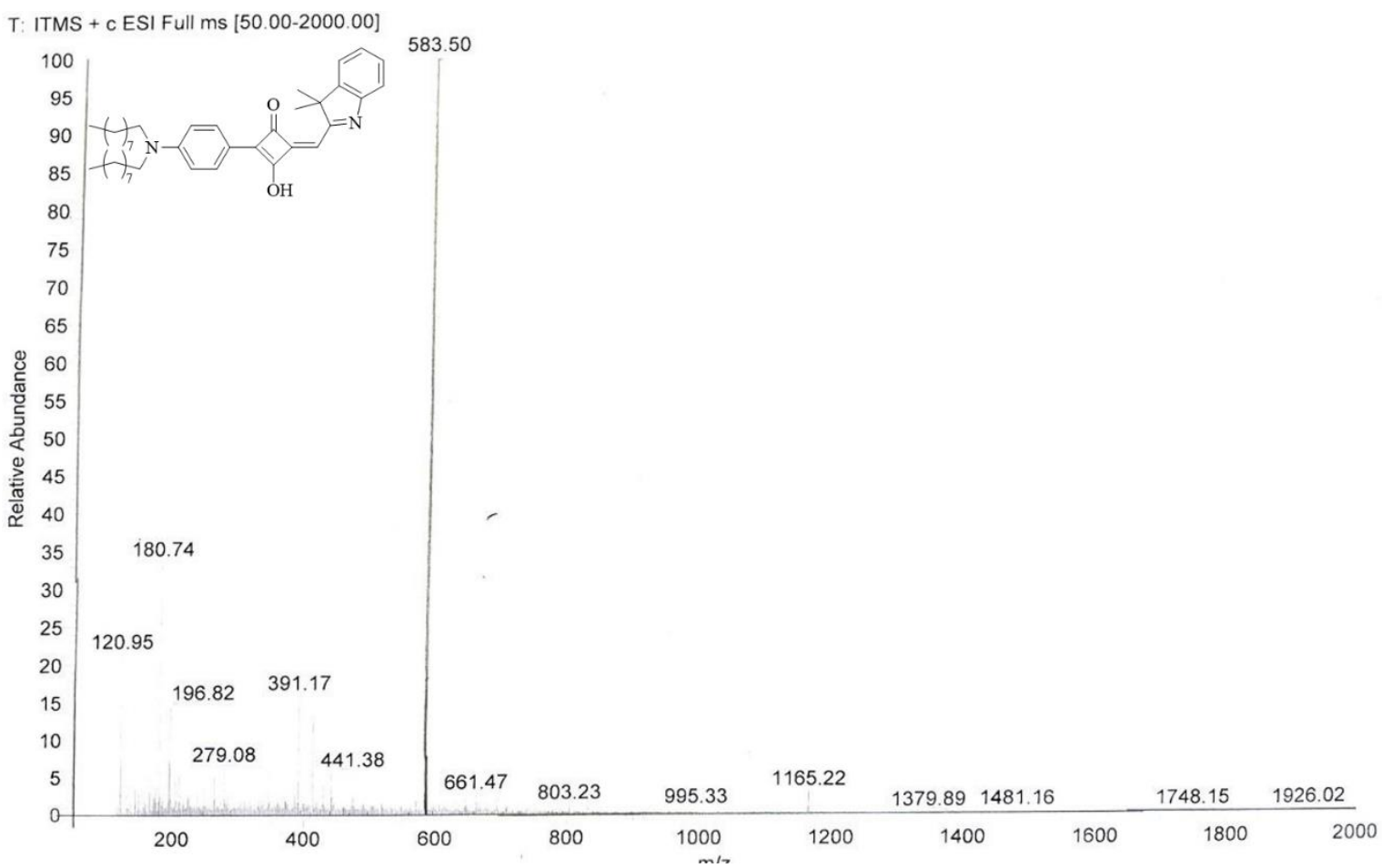

SQR27

${ }^{1} \mathrm{H}$ NMR

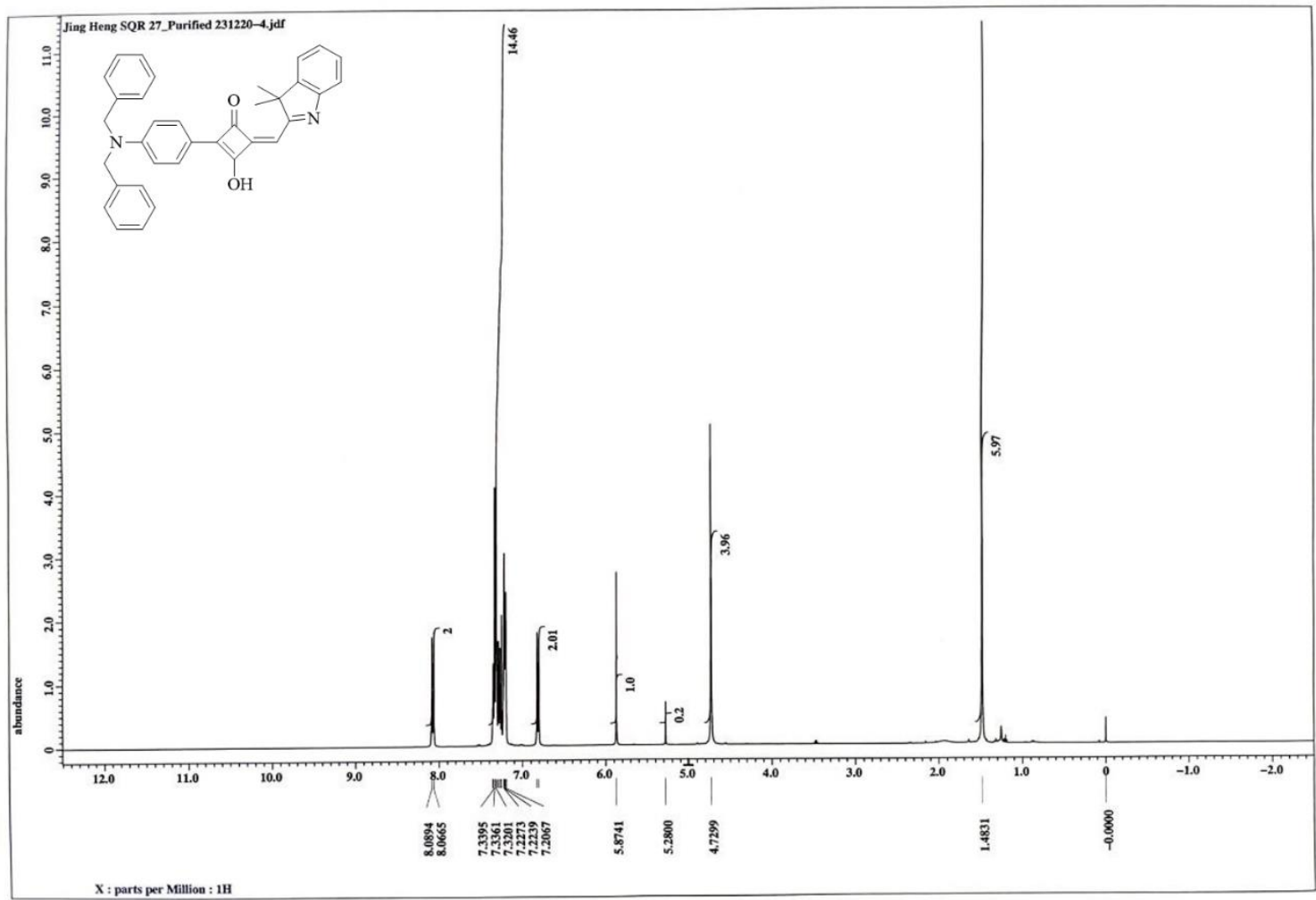


${ }^{13}$ C NMR

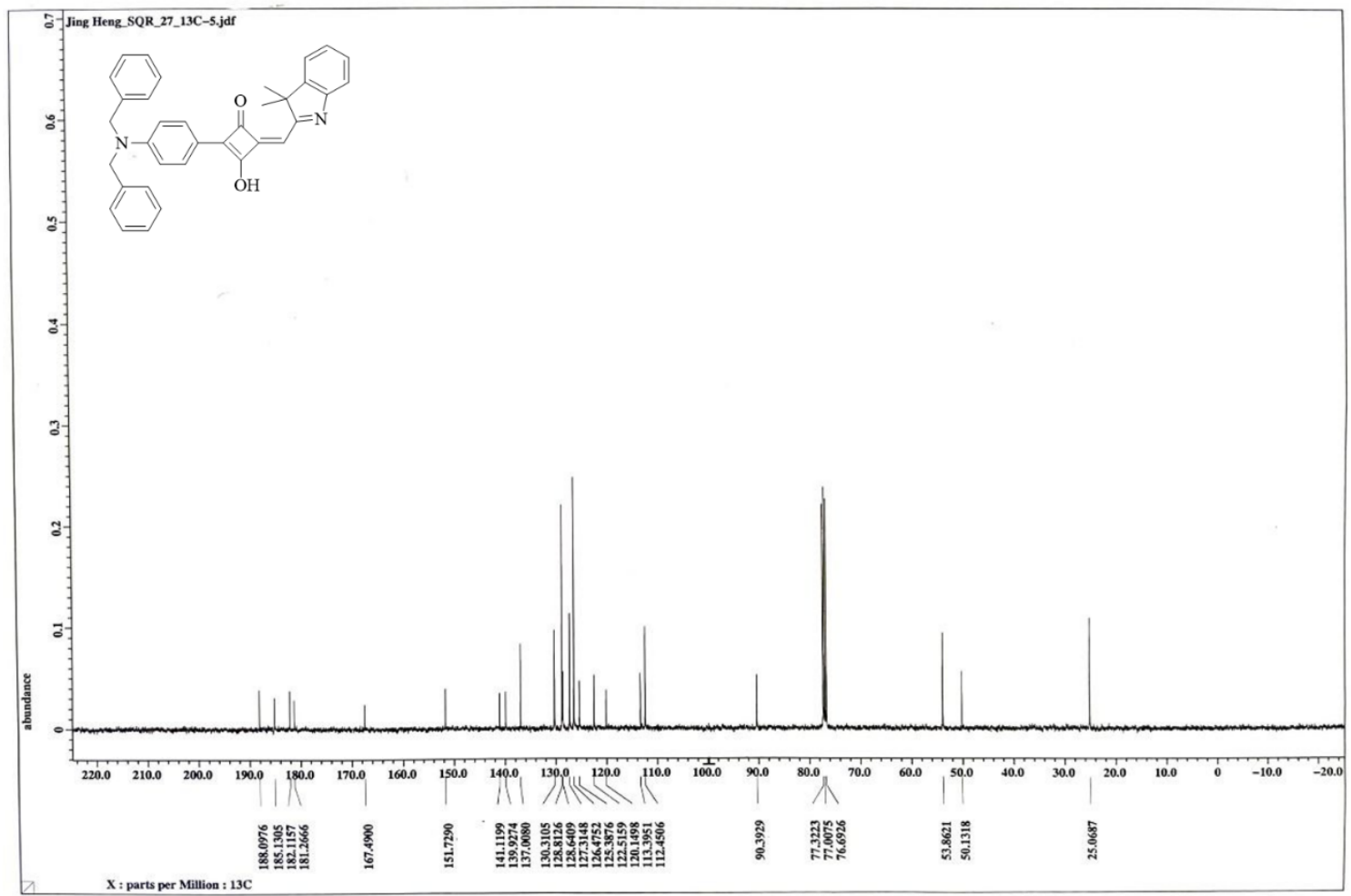

\section{ESI-MS}

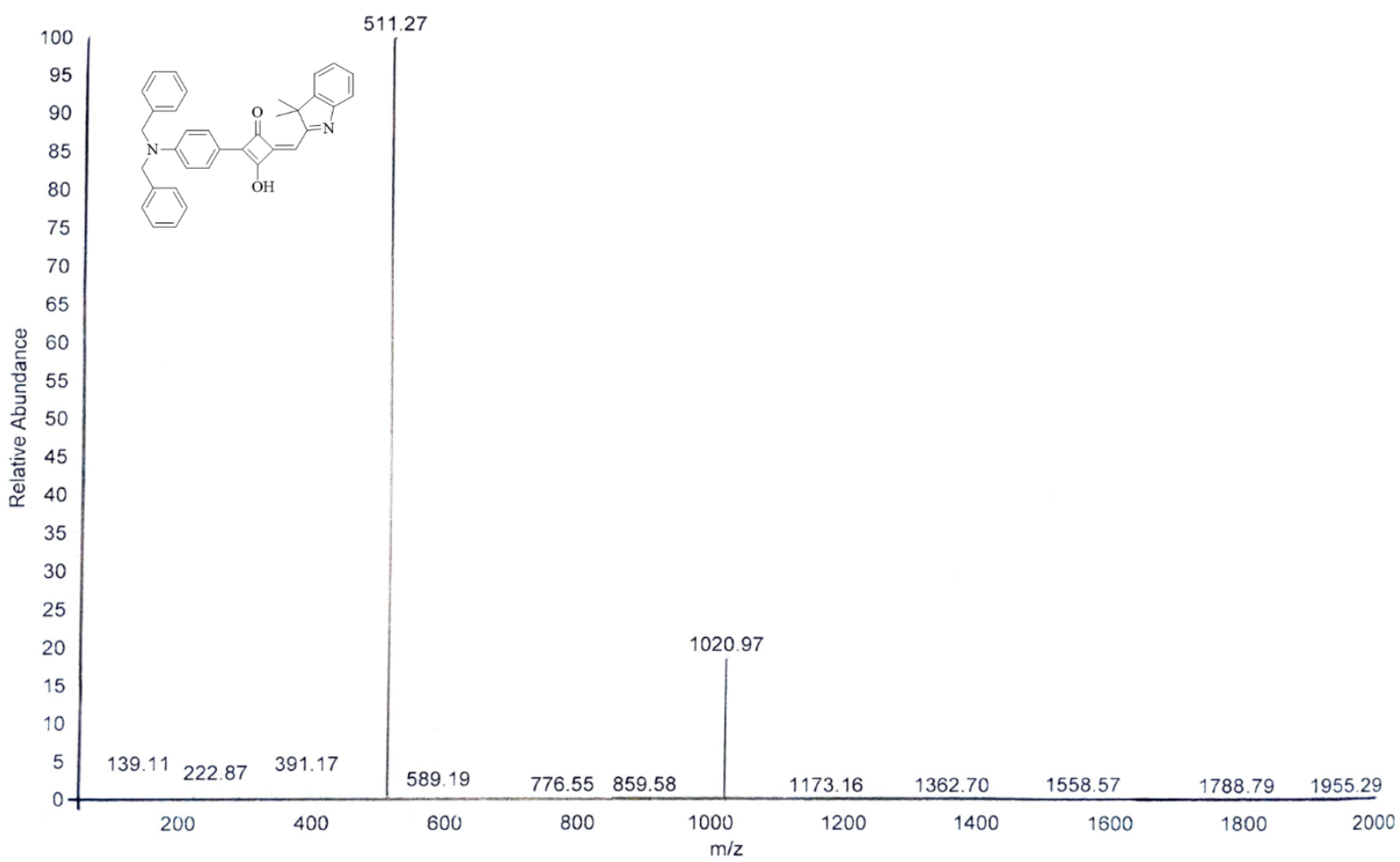


SQR30 (Compound 7)

${ }^{1}$ H NMR

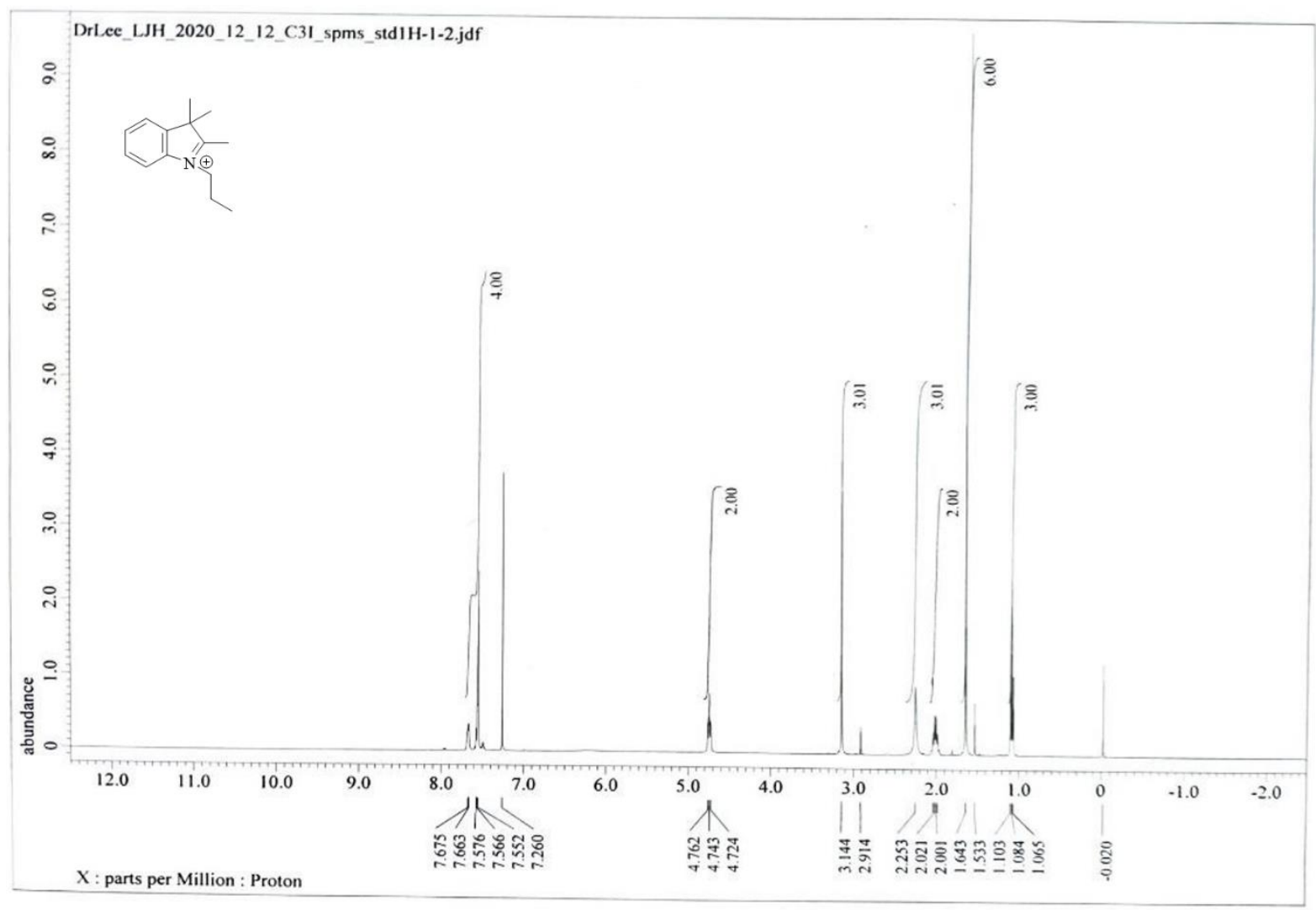

\section{ESI-MS}

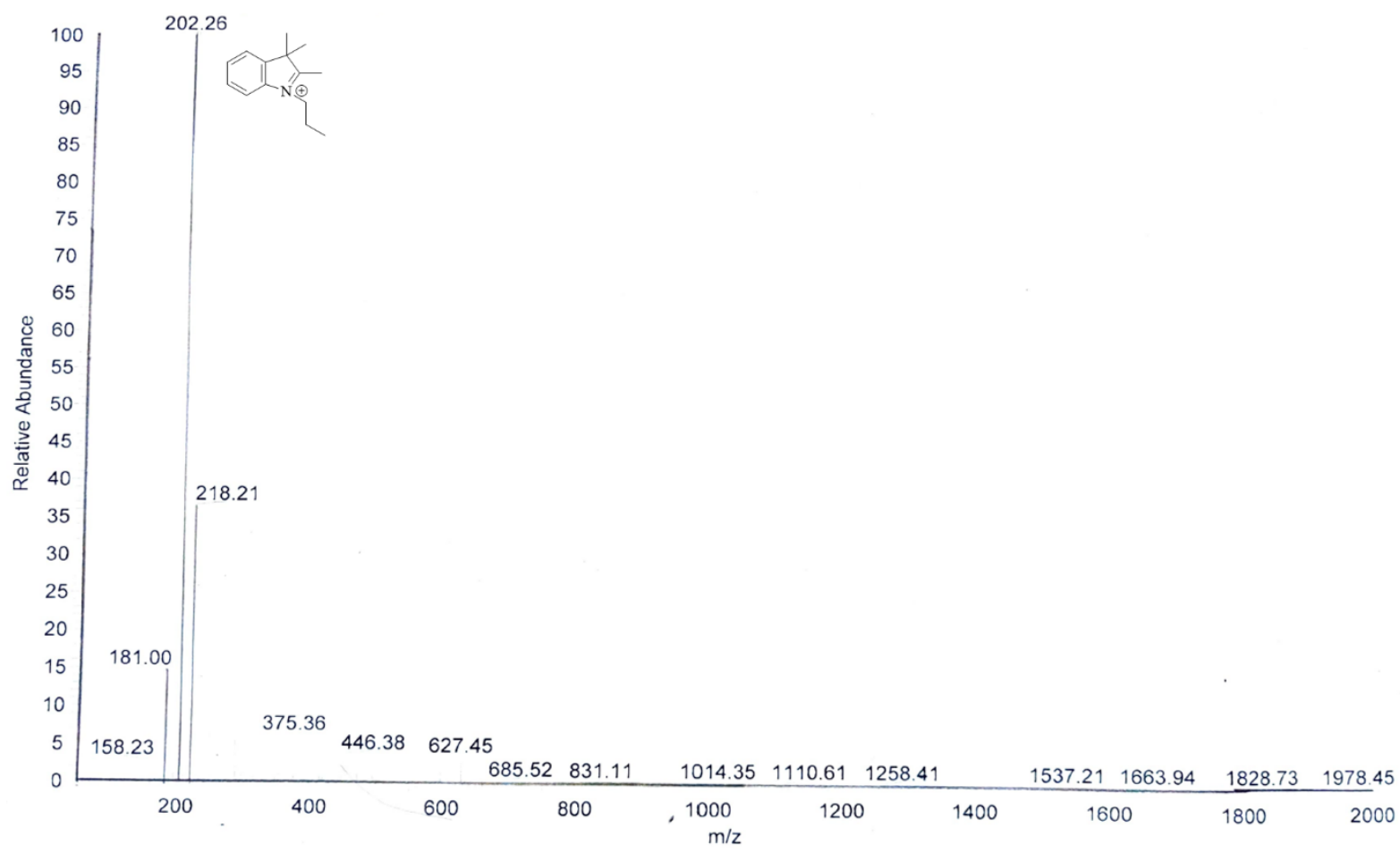


SQR30

${ }^{1} \mathrm{H}$ NMR

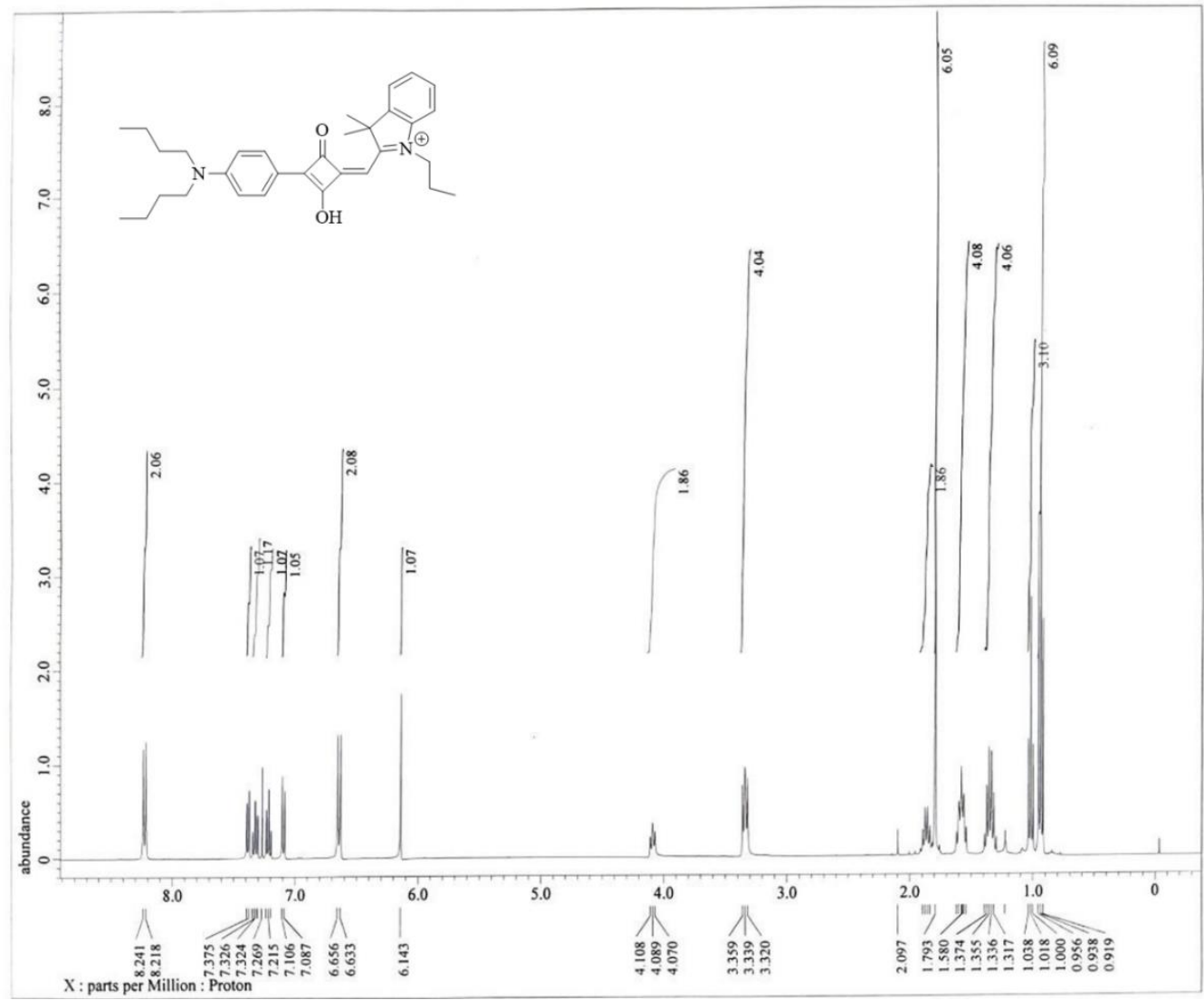

${ }^{13}$ C NMR

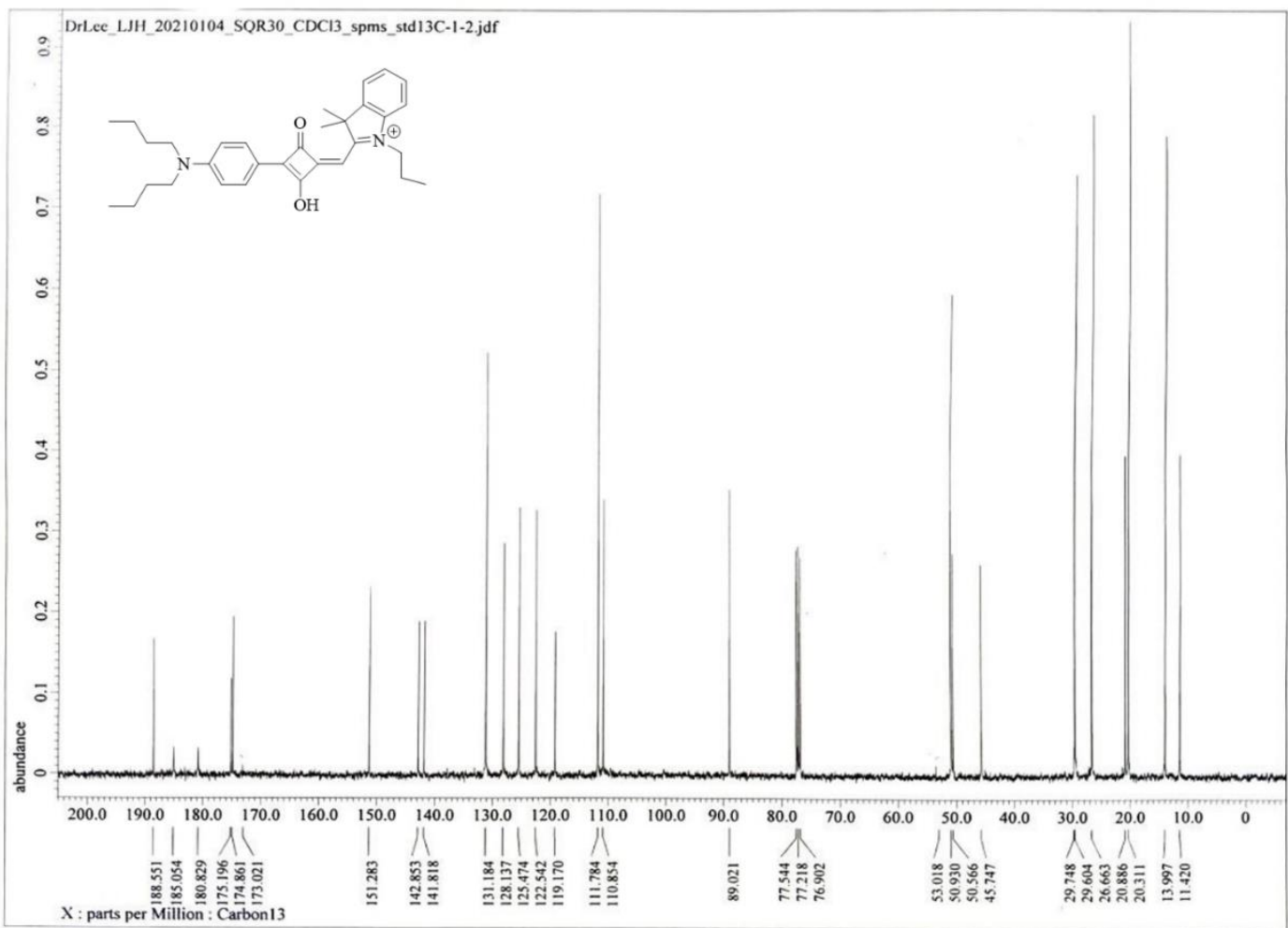




\section{ESI-MS}

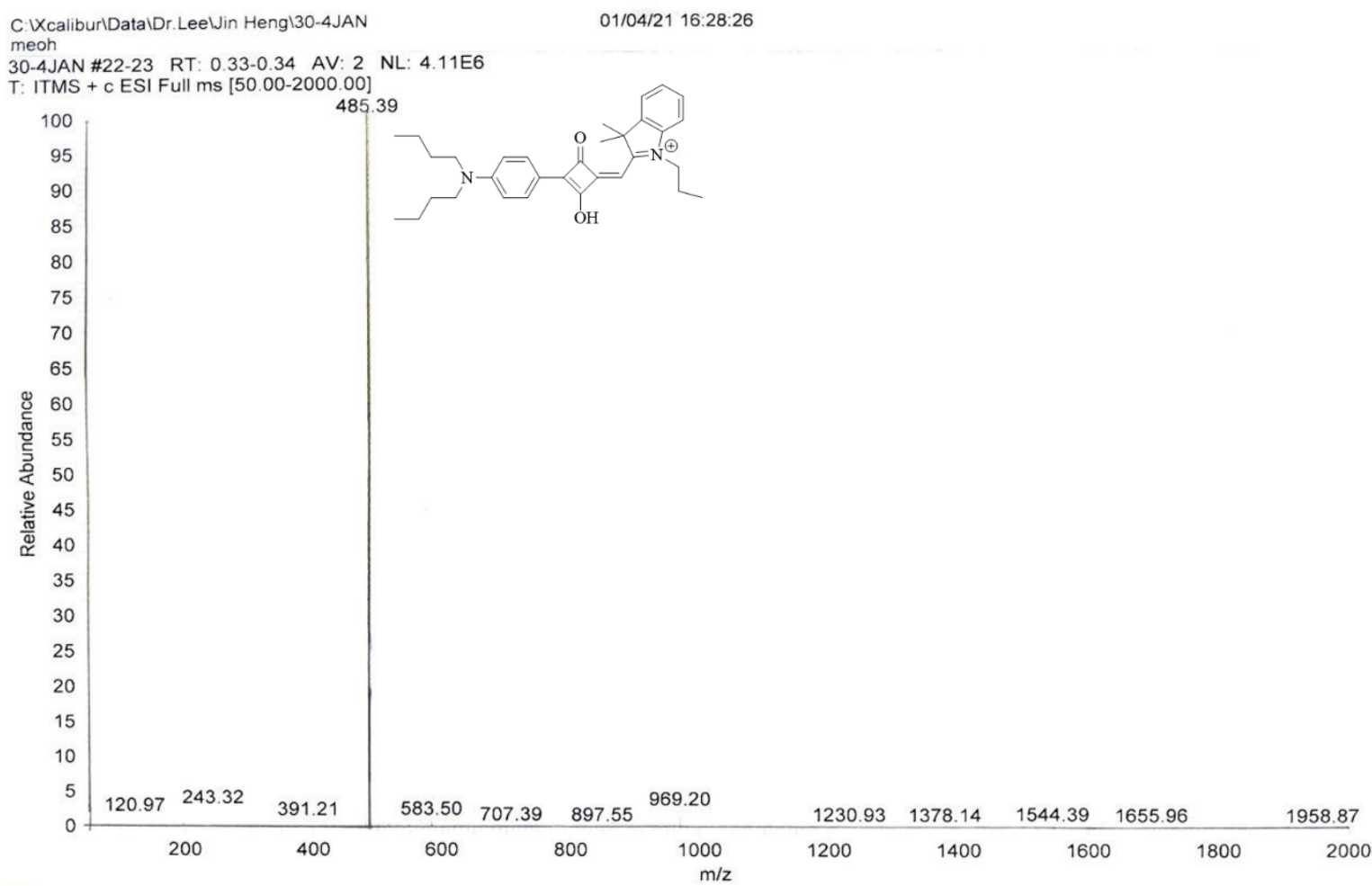

\section{Liposome Size and Zeta Potential}

Table S1. Summary of Size and Zeta Potential measurements for the 9 liposomes

\begin{tabular}{ccccc}
\hline Dye & {$[\mathrm{SQR}]$ in Liposome } & Average Size $(\mathrm{nm})$ & PDI & Average Zeta Potential $(\mathrm{mV})$ \\
\hline \multirow{3}{*}{ SQR26 } & $2.0 \%$ & $42.65 \pm 25.68$ & 0.184 & -7.69 \\
& $3.3 \%$ & $41.40 \pm 24.81$ & 0.194 & -8.41 \\
& $5.0 \%$ & $53.54 \pm 33.22$ & 0.223 & -7.9 \\
\hline \multirow{3}{*}{ SQR27 } & $2.0 \%$ & $49.91 \pm 30.68$ & 0.363 & -10.18 \\
& $3.3 \%$ & $78.28 \pm 43.46$ & 0.307 & -11.87 \\
& $5.0 \%$ & $61.77 \pm 42.91$ & 0.203 & -8.83 \\
\hline \multirow{3}{*}{ SQR30 } & $2.0 \%$ & $33.98 \pm 20.83$ & 0.261 & -11.63 \\
& $3.3 \%$ & $43.02 \pm 28.09$ & 0.174 & -12.13 \\
\hline
\end{tabular}




\section{DLS Spectra}

Figure S1. Size distribution of the 9 liposomes.
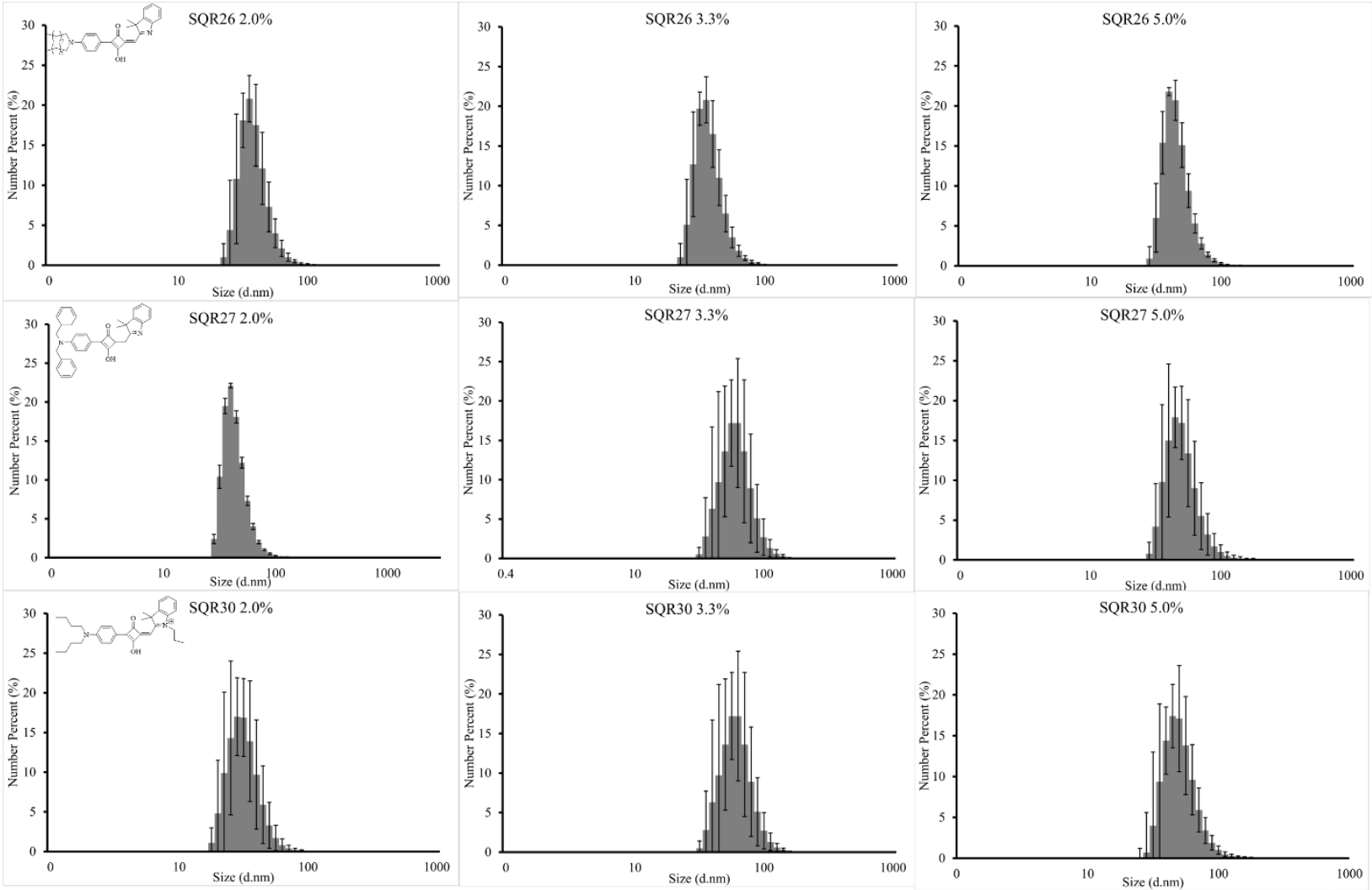


\section{Optical Characterization}

Native Dyes

UV-Vis Absorbance (Left) and Fluorescence (Right)
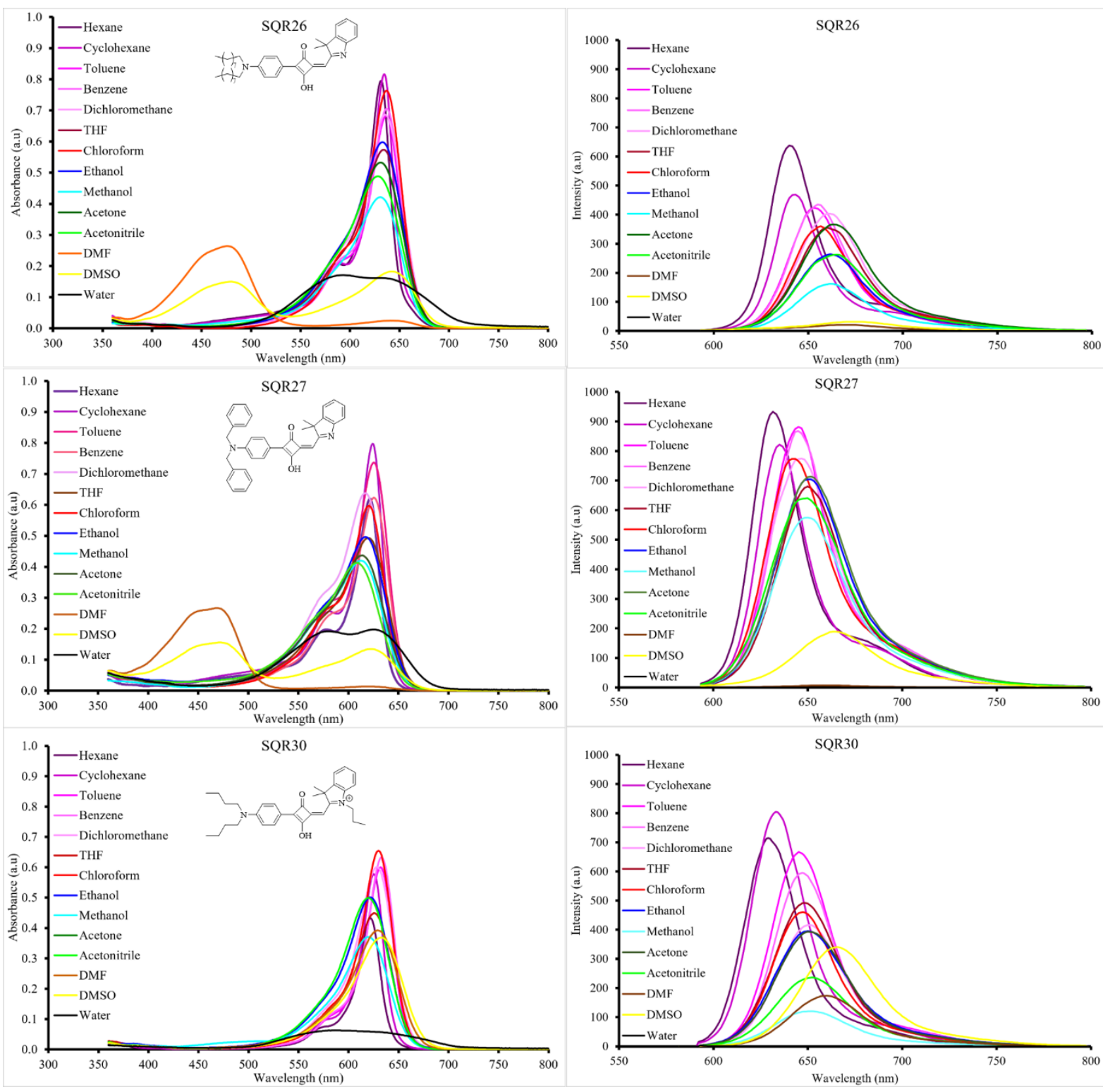


\section{Liposomes}

\section{UV-Vis Absorbance}
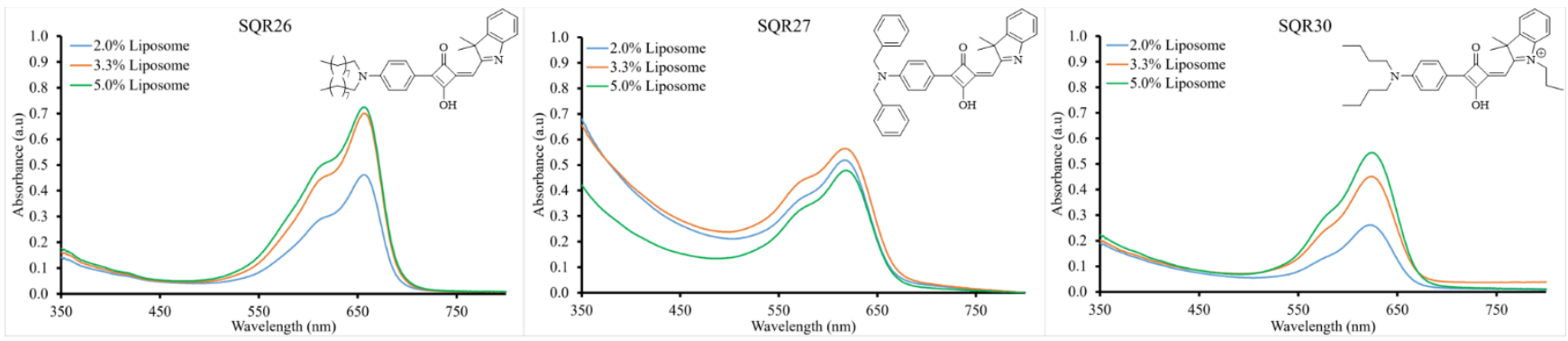

\section{Fluorescence}
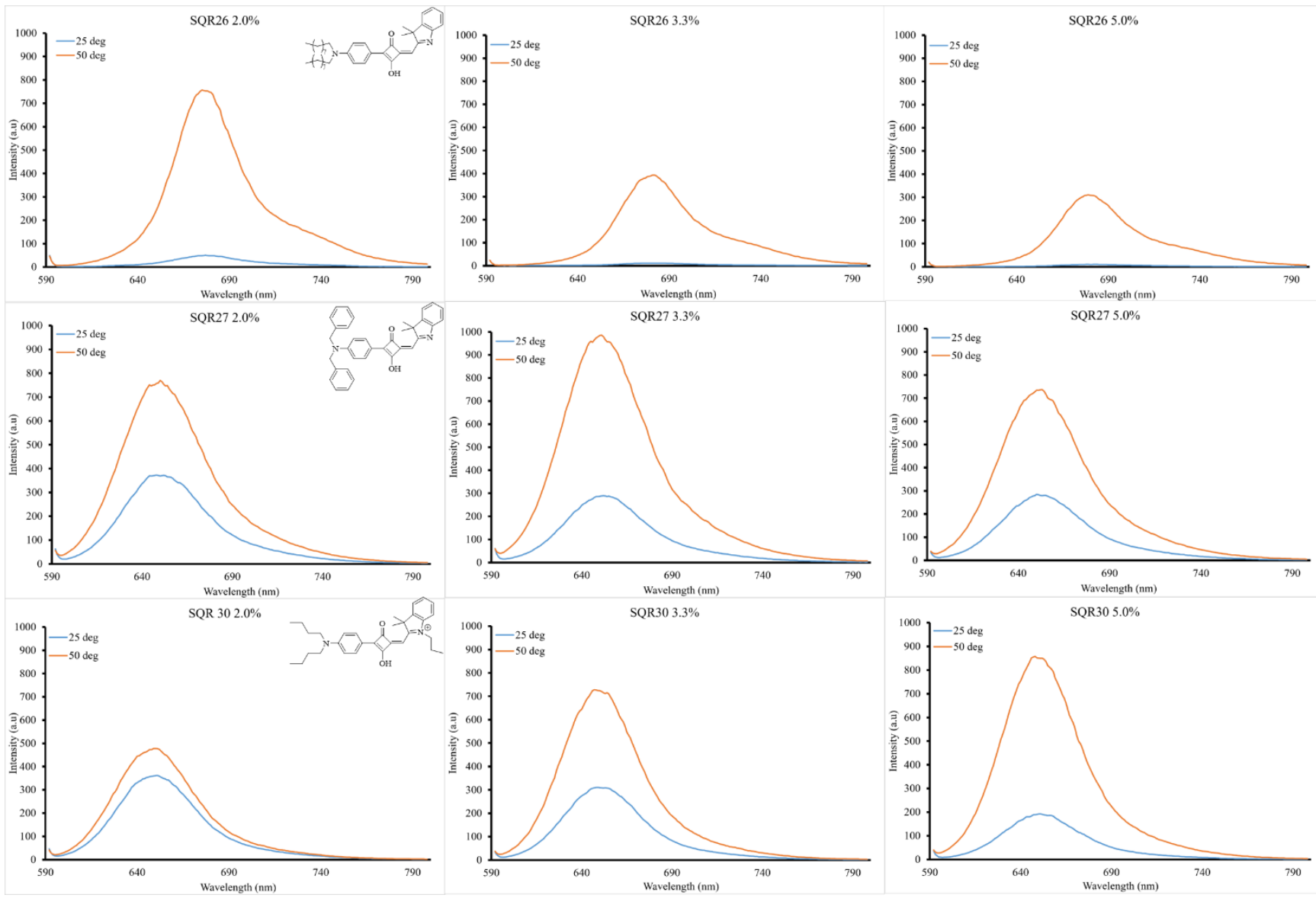